Esta revista forma parte del acervo de la Biblioteca Jurídica Virtual del Instituto de Investigaciones Jurídicas de la UNAM

\title{
La libertad de expresión y sus principales manifestaciones en el contexto de la democracia electoral mexicana*
}

\author{
César Astudillo \\ Imer B. Flores \\ Javier Patiño Camarena \\ María del Pilar Hernández \\ Daniel Márquez Gómez \\ John Ackerman \\ Hugo A. Concha Cantú \\ Susana Thalía Pedroza de la Llave \\ Julio A. Téllez Valdés**
}

\section{Sumario:}

I. La libertad de expresión en el contexto de un Estado (democrático) de derecho: una aproximación

II. La libertad de expresión y su influjo en el modelo de comunicación político-electoral

* El presente artículo representa la síntesis del proyecto de investigación "La libertad de expresión y sus principales manifestaciones en el contexto de la democracia mexicana", desarrollado por el área de Derecho Electoral del Instituto de Investigaciones Jurídicas de la UNAM bajo el patrocinio del Fondo de Apoyo a la Observación Electoral 2012, administrado por el PNUD. Se agradece el apoyo otorgado en la investigación, así como en la preparación y revisión del texto de la maestra Caridad G. Hernández Zenteno, y los maestros Marcos I. Martínez Alcázar y David Alonso Canales.

** Investigadores en el Instituto de Investigaciones Jurídicas de la UNAM. 
Esta revista forma parte del acervo de la Biblioteca Jurídica Virtual del Instituto de Investigaciones Jurídicas de la UNAM

\author{
III. Libertad de expresión y el derecho a la información en \\ los documentos básicos de los partidos políticos \\ IV. Libertad de expresión en el ámbito electoral y sus \\ operadores jurídicos \\ V. Instituciones electorales, derecho a la información y \\ medios de comunicación en las campañas presidenciales \\ de 2012 \\ VI. La promoción del voto razonado mediante la \\ organización de debates electorales \\ VII. La libertad de expresión y el derecho de réplica \\ VIII. Libertad de expresión en Internet y redes sociales en la \\ democracia en México: aproximación jurídica en materia \\ electoral \\ IX. Fuentes consultadas
}

\title{
Resumen:
}

La libertad de expresión constituye un elemento clave e imprescindible en cualquier democracia constitucional por la trascendencia de los mensajes a través de los cuales se expresan opiniones e ideas eminentemente políticas con finalidades claramente electorales. Derivado de su relevancia para la salud de la democracia mexicana, la presente contribución se propone determinar en qué medida el modelo de comunicación política introducido por la reforma constitucional electoral de 2007 favorece o condiciona la libertad de expresión; advertir la forma como los propios partidos políticos conciben la libertad de expresión como prerrogativa de sus propios militantes y simpatizantes, y cómo la contemplan como objeto de políticas públicas; determinar cuál es el contenido y alcance de dicha libertad fundamental, de conformidad con la interpretación que le han conferido las instituciones electorales de nuestro país; analizar la función de los medios de comunicación y la garantía del derecho a la información en el contexto de las campañas electorales; determinar el grado en que los debates coadyuvan a la promoción de un voto consciente y razonado; subrayar la importancia que para la deliberación pública y la socialización de información política ejerce el derecho de réplica, y exponer el papel de las plataformas tecnológicas y las redes sociales en la maximización de los mensajes de contenido político-electoral.

Palabras clave: libertad de expresión, derecho a la información, modelo de comunicación político-electoral, debates, derecho de réplica. 


\section{La libertad de expresión en el contexto de un Estado (democrático) de derecho: una aproximación}

\section{Introducción}

Reflexionar sobre la libertad de expresión en el contexto de un Estado (democrático) de derecho es el tema genérico que nos ocupa en este trabajo colectivo. Ahora bien, el problema específico es determinar si la reforma a la Constitución mexicana en materia electoral publicada en el Diario Oficial de la Federación (DOF) del 13 de noviembre de 2007, en general, y el modelo de comunicación político-electoral que la misma consagró, en particular, son compatibles o no con la libertad de expresión y su ejercicio, al facilitar su expresión en condiciones de equidad.

\section{Consideraciones analíticas y conceptuales}

\section{A. Estado de derecho}

A pesar de que el concepto de "Estado de derecho" es problemático, comúnmente está asociado con nociones tales como: el "gobierno de (las) leyes", el "estado de (la) razón” y el rechtstaat en contraposición al "gobierno de (los) hombres", al "estado de (la) pasión" y al machtstaat, bajo la forma de "estados autoritarios" o "totalitarios", respectivamente; el "imperio del derecho", identificado con la expresión en inglés: rule of law; y con las caracterizaciones, ya sea como "Estado liberal de derecho" al cual se le puede contraponer en el pasado el "Estado social de derecho" y en la actualidad el "Estado democrático de derecho", o bien como "Estado legislativo de derecho" al cual se le ha contrapuesto recientemente el "Estado constitucional de derecho". ${ }^{1}$

1 Véase Zagrebelsky, Gustavo, El derecho dúctil. Ley, derechos, justicia, trad. de Marina Gascón, 2a. ed., Madrid, Trotta, 1997, pp. 21-45; Ferrajoli, Luigi, “Jueces y política”, Derechos y libertades, Revista del Instituto Bartolomé de las Casas, Año IV, núm. 7, enero, 1999, pp. 63-79. Véase también Flores, Imer B., "Constitución, democracia y derecho: 
Esta revista forma parte del acervo de la Biblioteca Jurídica Virtual del Instituto de Investigaciones Jurídicas de la UNAM

Así, el "Estado liberal de derecho" se caracteriza por insistir en la generalidad de la ley y su obediencia, a partir de principios tales como "la igualdad ante la ley", la "prohibición a la creación de leyes o tribunales especiales", la "certeza o seguridad de la ley", y el "debido proceso de ley". Ahora bien, ante los extremos formales de los ideales que inspiraron el "Estado liberal de derecho" aparece primero el "Estado social de derecho" con su clamor por la igualdad, la justicia y hasta la equidad social, ${ }^{2}$ y, después el "Estado democrático de derecho", el cual aspira a que la igualdad no sea meramente formal ante la ley sino también material en la ley al garantizar la igualdad de todos los seres humanos en todos los derechos humanos, sin importar su condición económica, política o social, edad, género, origen étnico, racial o nacional. $^{3}$

\section{B. Libertad}

La palabra "libertad", i. e. libertatem, deriva del latín libertas, - atisy denota la condición del ser humano que no está sujeto a ninguna forma de esclavitud o de servidumbre y como consecuencia a la condición de ser libre, i. e. libero, y tener la capacidad para realizar toda una serie de actividades. Asimismo, es representada por una mujer que ha roto las cadenas que la mantenían subyugada y connota la lucha tanto en contra de cualquier forma de opresión como a favor de su liberación en busca de su independencia y de la posibilidad de realizarse a sí misma, i. e. de su autorrealización.

$\mathrm{Al}$ respecto, la noción anterior ha dado lugar a dos grandes modelos: uno, el de la antigüedad o republicano, donde se privilegia la libertad colectiva o política y, por ello, a la igualdad y a la comunidad; $y$, otro, el de la modernidad o liberal, donde se privilegia la libertad individual o civil y, por ende, a la libertad y a la individualidad. En

teoría constitucional y valores constitucionales", Revista del Instituto de la Judicatura Federal, núm. 13, 2003, pp. 145-159.

2 Véase Flores, Imer B., "Equidad social”, en Fix-Zamudio, Héctor y Valadés, Diego (eds.), Instituciones sociales en el constitucionalismo contemporáneo, 2a. ed., México, El Colegio Nacional-UNAM, Instituto de Investigaciones Jurídicas, 2011, pp. 137-165.

3 Véase Flores, Imer B., "Igualdad, no discriminación (y políticas públicas): A propósito de la constitucionalidad o no del artículo 68 de la Ley General de Población”, en De la Torre Martínez, Carlos (coord.), El derecho a la no discriminación, México, UNAM, Instituto de Investigaciones Jurídicas, 2006, pp. 263-306. 
Esta revista forma parte del acervo de la Biblioteca Jurídica Virtual del Instituto de Investigaciones Jurídicas de la UNAM

otras palabras, al igual que en el caso del Estado de derecho, hay una cierta tensión entre dos modelos y sus respectivas condiciones: una positiva como autodeterminación, $y$, otra, negativa como ausencia de coerción. La primera equiparada con una libertad "para" comunitaria, democrática o republicana, $y$, la segunda identificada con una libertad "de" propiamente liberal. ${ }^{4}$

\section{Libertad de expresión}

La libertad de expresión consagra la posibilidad de manifestar creencias, opiniones o pensamientos sin limitaciones de ningún tipo, salvo aquéllas que estén expresamente consagradas y como tales justificadas o legitimadas en el principio de no dañar a otros. Asimismo, resulta clara la existencia no sólo de un hilo conductor entre la libertad de opinión y de pensamiento, la libertad de expresión y la libertad de imprenta, sino también con otros derechos y libertades, tales como el derecho - o libertad- de información y el derecho de réplica.

Al igual que en los casos del "Estado de derecho" y de la "libertad" resulta que existen al menos dos modelos para explicar la libertad de expresión: uno liberal y otro democrático. ${ }^{5}$ Así, en el primero: la libertad de expresión es una libertad civil e individual; el beneficiario de su protección es el individuo, en especial el crítico o disidente, ${ }^{6}$ el cual

4 Bobbio, Norberto, Liberalismo y democracia, trad. de José Fernández Santillán, México, Fondo de Cultura Económica, 1989; e Igualdad y libertad, trad. de Pedro Aragón Rincón, Barcelona, Paidós, 1993.

5 En los últimos años ha sido Owen Fiss, quien ha desarrollado dos modelos doctrinales respecto a la libertad de expresión, mismos que caracterizó como "libertario" y "democrático". Véase Fiss, Owen, The Irony of Free Speech, Cambridge, Massachusetts, Harvard University Press, 1996. Al respecto, coincidimos con Alejandro Madrazo Lajous, en el sentido de que usar la etiqueta "libertario" no es del todo afortunada ni correcta porque parece sugerir que no hay límites y en lugar de utilizar la de "clásico" o "liberal clásico" hemos optado por la de "liberal". Véase Madrazo, Lajous, Alejandro, "Libertad de expresión y equidad. La reforma electoral de 2007 ante el Tribunal Electoral”, Cuadernos de divulgación de la Justicia Electoral, México, TEPJF, núm. 5, 2008, pp. 15-30.

6 Cabe recordar que dos ministros de la SCJN, en su voto de minoría en el Amparo en Revisión 2676/2003, conocido como el caso... "bandera", "del poeta maldito", "de Sergio Hernán Witz Rodríguez", y fallado por la Primera Sala el 5 de octubre de 2005, afirmaron que la libertad de expresión protege "no solamente la manifestación de ideas que comparte con la gran mayoría de sus conciudadanos, sino también de ideas impopulares, provocativas o, incluso, aquellas que ciertos sectores de la ciudadanía considera ofensivas. La libertad de expresión es, en muchos sentidos, un derecho al disenso." Citado 
Esta revista forma parte del acervo de la Biblioteca Jurídica Virtual del Instituto de Investigaciones Jurídicas de la UNAM

como emisor tiene el beneficio de poder expresar sus opiniones y pensamientos, y el Estado no debe intervenir salvo en el caso de que en el ejercicio de su libertad de expresión pueda dañar a otros individuos. En cambio, en el segundo: la libertad de expresión es una libertad política y colectiva; el beneficiario de su protección no es el individuo en sí sino la comunidad, la cual como receptora tiene el beneficio de una diversidad y hasta pluralidad de opiniones y pensamientos; y el Estado debe intervenir para garantizar no sólo dicha diversidad y hasta pluralidad de opiniones y pensamientos sino también la equidad a las que concibe como necesarias para la deliberación pública.

\section{Consideraciones dialécticas y funcionales: la libertad de expresión, la reforma electoral y el modelo de comunicación político-electoral}

Tanto el modelo liberal como el democrático admiten la posibilidad de establecer limitaciones a la libertad de expresión. No obstante, dichas restricciones para estar justificadas deben ser coherentes con el modelo mismo. Así, en principio, en el liberal es posible limitar la libertad de expresión de un individuo para evitar que pueda dañar a otro(s) individuo(s), en cambio en el modelo democrático es posible limitar la libertad de expresión para fomentar mediante el ejercicio de otros derechos no sólo la diversidad y hasta la pluralidad de opiniones y pensamientos al interior de la comunidad sino también su equidad, para que el individuo pueda estar en condiciones de tomar decisiones razonadas e informadas.

De tal suerte, como se puede apreciar, la Constitución mexicana combina en la actualidad elementos de ambos modelos tanto del liberal como del democrático. Es más, la reforma a la Constitución mexicana en materia electoral, publicada en el DOF del 13 de noviembre de 2007 , en respuesta ya sea a los excesos o defectos tanto del marco jurídico anterior, como de su aplicación sobre todo en el proceso electoral de 2006, en general, y de la elección presidencial, en particular, esta-

\footnotetext{
por Cruz Parcero, Juan Antonio, "La libertad de expresión y los límites impuestos por la reforma del artículo 41 constitucional. Aspectos problemáticos”, en Córdova Vianello, Lorenzo y Salazar Ugarte, Pedro (coords.), Estudios sobre la reforma electoral 2007. Hacia un nuevo modelo, México, TEPJF, 2009, p. 283.
} 
Esta revista forma parte del acervo de la Biblioteca Jurídica Virtual del Instituto de Investigaciones Jurídicas de la UNAM

bleció un "nuevo" modelo de comunicación político-electoral, ${ }^{7}$ caracterizado entre otras cosas por: 1) elevación a rango constitucional del derecho de réplica; 2) inclusión de la prohibición de la difamación y las calumnias, y 3) incorporación de la prohibición para la contratación de publicidad y tiempo en radio y televisión.

Como se puede advertir la justificación de las dos primeras obedece a la lógica del modelo liberal y al principio de no dañar a otros. Por su parte, la justificación de la tercera obedece a los principios del modelo democrático más que a los del liberal. Así, en los tres últimos párrafos del apartado A de la fracción III del artículo 41 constitucional, el órgano revisor de la Constitución mexicana estableció una serie de prohibiciones relativas a la compra y/o contratación de tiempos y publicidad en radio y televisión por parte no sólo de los partidos políticos, por sí o por otros, sino también por parte de los particulares, ya sean personas físicas o morales, así como a la transmisión de mensajes contratados en el extranjero.

En lo referente a la prohibición a los partidos políticos para contratar tiempos en radio y televisión, habría que aclarar que no se canceló la contratación de tiempos sino que se limitó que los partidos hicieran la contratación con los medios masivos de comunicación y en cambio se requirió que fuera el Instituto Federal Electoral (IFE) el que administrara las pautas para su contratación y transmisión. Lo anterior con la idea de evitar la posibilidad de un trato diferenciado o preferencial, y de garantizar la equidad en el acceso a los medios masivos de comunicación, así como en su transmisión.

En lo relativo a la prohibición a particulares para contratar publicidad habría que precisar que el Código Federal de Instituciones y Procedimientos Electorales (Cofipe) contemplaba que los particulares solamente podían contratar publicidad para la promoción del voto pero no para hacer campaña a favor ni en contra de los partidos y de sus candidatos. Sin embargo, ante los excesos de quienes abiertamente hicieron campaña a favor de un candidato y/o en contra del otro, así como los defectos de las autoridades electorales, el órgano revisor de la Constitución mexicana optó por ampliar los alcances de la prohibición y elevar la misma a rango constitucional. Aun cuando, la medida

7 Véase Astudillo, César, "El nuevo sistema de comunicación política en la reforma electoral de 2007", en Córdova Vianello, Lorenzo y Salazar Ugarte, Pedro (coords.), Estudios sobre la reforma electoral 2007. Hacia un nuevo modelo, México, TEPJF, 2009, t. I, pp. 175-251. 
Esta revista forma parte del acervo de la Biblioteca Jurídica Virtual del Instituto de Investigaciones Jurídicas de la UNAM

puede parecer un tanto paternalista y como tal se suma a los aspectos controvertidos de la reforma, resulta que el objeto, además de evitar la campaña negativa, era mantener la equidad en la contienda electoral.

Aunado a los tres aspectos anteriores, la reforma contemplaba mayores espacios a la autoridad electoral para interferir, ya sea al autorizar los contenidos de la propaganda político-electoral o al elaborar los lineamientos generales que deben observar los concesionarios de los medios masivos de comunicación. Como es sabido, hubo quienes - sobre todo los concesionarios de la radio y televisión, un grupo de "intelectuales", y los representantes de algunos partidos políticosestimaron que la reforma había sido excesiva al restringir entre otras cosas la libertad de expresión y que como tal debería ser declarada inconstitucional. Al respecto, me gustaría enfatizar que somos de la opinión que la reforma en ningún momento restringió indebidamente la libertad de expresión, puesto que los límites impuestos al derecho a contratar tiempos y publicidad en radio y televisión, así como la regulación de los contenidos de la propaganda electoral con el ánimo de no dañar a nadie y de contribuir a la formación de una opinión libre e informada en ningún momento cancelaron la libertad de expresión ni constituyen una forma de censura previa. Insisto, que la prohibición de contratación a los particulares en medios masivos de comunicación en nada afecta la libertad de expresión y para muestra de ello, me permito mencionar que a través de la diferentes redes, sobre todo las sociales, en el pasado proceso electoral fue posible expresar en todo momento y con toda libertad sus opiniones y pensamientos.

Si bien, el modelo de comunicación político-electoral adoptado por la reforma constitucional y legal en materia electoral de 2007-2008 tiene aspectos controvertidos y hasta problemáticos, está justificado en parte en el modelo liberal al evitar dañar a otros, de un lado, y en parte en el democrático, al facilitar la participación de todos en condiciones de equidad en el debate y la deliberación, así como en la toma de decisiones razonadas e informadas, del otro. 


\section{La libertad de expresión y su influjo en el modelo de comunicación político-electoral}

\section{Introducción}

Desde su implantación en la reforma electoral de 2007, el modelo de comunicación político-electoral ha sido objeto de polémica. Sus detractores afirman que vulnera la libertad de expresión al prohibir la comunicación política a través de la libre contratación de spots electorales; quienes lo respaldan, por el contrario, sostienen que el modelo es compatible con aquellos sistemas democráticos que auspician la paridad de condiciones en la competencia política e impiden que el factor oneroso sea determinante en las posibilidades de triunfo de sus contendientes.

Las líneas que enseguida se ponen a consideración de los lectores tienen por objeto analizar la vinculación entre la libertad de expresión y el modelo de comunicación político-electoral, ofrecer argumentos para afirmar que éste no vulnera la libertad de expresión sino que la modula en concordancia con el principio constitucional de equidad y, sobre todo, subrayar las deficiencias institucionales que no favorecen la fluidez de la comunicación en el espacio político-electoral, y que dificultan la circulación de una mayor riqueza de contenidos y una información de más calidad, elementos todos que se consideran indispensables para la emisión de un voto consciente y razonado.

\section{El modelo de comunicación político-electoral y sus implicaciones con el ejercicio de la libertad de expresión}

No decimos nada nuevo al afirmar que los agentes de la política necesitan un canal de comunicación con el ciudadano, pieza clave del entramado democrático por su calidad de elector, ante quien se despliegan debates y deliberaciones, se presentan discursos y se allega información con el objetivo de mantener su interés en lo que acontece en la escena pública para que pueda manifestar su adhesión a las de- 
Esta revista forma parte del acervo de la Biblioteca Jurídica Virtual del Instituto de Investigaciones Jurídicas de la UNAM

cisiones tomadas o expresar su simpatía por una determinada fuerza política al interior de una campaña electoral. ${ }^{8}$

Como consecuencia de lo anterior, un rasgo distintivo de la democracia reside en su inescindible vinculación con la comunicación política, disciplina interesada en el papel que ejerce la comunicación dentro del proceso político y en la manera como la política es comunicada por quienes la ejercen - los políticos-, por quienes la transmiten - los medios de comunicación - y por quienes la reciben — los ciudadanos -.$^{9}$

El conjunto de interacciones que se produce entre los sujetos del proceso comunicativo presupone, a su vez, un régimen de libertades plenas amparadas por el orden constitucional. Dentro de dicho concierto de libertades públicas, la libertad de expresión adquiere una relevancia significativa al ofrecer la cobertura jurídica para que las personas exterioricen libremente sus ideas, pensamientos y críticas. Es, de hecho, una libertad pública incuestionable y, a su vez, el fundamento de otras libertades públicas igualmente relevantes para el orden democrático, como la libertad de reunión y asociación, el derecho a la información, la libertad de imprenta, el derecho a la honra, la dignidad, y como correlato, los derechos de participación política. De ahí que su global consideración las agrupe en un régimen de libertades de más amplio alcance y las erija en auténticas libertades de comunicación, sean públicas o sociales. ${ }^{10}$

En el ámbito de la competencia electoral, la libertad de expresión permite socializar mensajes de contenido político, difundir programas, ideologías y plataformas, confrontar ideas y propuestas de campaña, ejercer la crítica hacia los miembros de la clase política y los

8 En torno a la vinculación entre libertad de expresión, democracia y comunicación político-electoral, acúdase a Astudillo, César, "La libertad de expresión en el contexto del modelo de comunicación político-electoral", Revista Mexicana de Derecho Electoral, núm. 3, México, UNAM, Instituto de Investigaciones Jurídicas, enero-junio 2013, pp. 6 y ss; Carbonell, Miguel, "La libertad de expresión en materia electoral”, Temas selectos de Derecho Electoral, núm. 3, México, TEPJF, 2010; Madrazo, Lajous, Alejandro, "Libertad de expresión... op. cit.

9 Véase Chaffe, Steven (comp.), Political comunication, Beverly Hills, Sage, 1975, p. 15; en general, Mazzoleni, Gianpietro, La comunicación política, trad. de Josefa Linares de la Puerta, Madrid, Editorial Alianza, 2010; Rospir, Juan Ignacio, "Introducción a la comunicación política”, en Salomé Berrocal, Gonzalo (coord.), Comunicación política en televisión y nuevos medios, Barcelona, Ariel, 2003.

10 Polo Sabau, José Ramón, Libertad de expresión y derecho de acceso a los medios de comunicación, Madrid, Centro de Estudios Políticos y Constitucionales, 2002, pp. 15 y ss. 
partidos políticos, debatir en torno a los resultados de la gestión pública, transmitir spots con voces o imágenes propagandísticas, enviar información con contenido electoral, entrar en diálogo directo con los candidatos y sus partidos y, en el extremo, posibilitar la expresión de las preferencias políticas mediante el ejercicio directo del sufragio. Como consecuencia de lo anterior, allí donde el ejercicio de la libertad de expresión es robusto el sistema democrático se enriquece; pero se consolida únicamente en la medida en que logre garantizar el goce efectivo de derechos y libertades políticas. En este sentido, la recíproca implicación entre la libertad de expresión y la democracia es evidente.

Para que la libertad de expresión ejerza la totalidad de sus potencialidades requiere de una intervención legislativa, sea constitucional $\mathrm{u}$ ordinaria, que mediante reglas formales racionalice su ejercicio de conformidad con los distintos ámbitos en los que se manifiesta, sea para ampliar las vías de expresión de determinados sujetos políticos, potenciar el debate, la propuesta, la confrontación, la crítica; maximizar los canales para la libre circulación de información electoral, abrir o limitar las voces que pueden enviar mensajes de contenido político, o bien restringir el contenido de dichos mensajes.

La reforma electoral de noviembre de 2007, constata una intervención fuerte del legislador mexicano sobre la cobertura jurídica de la libertad de expresión, al establecer una regulación precisa respecto a: a) la modalidad de acceso de los partidos políticos a los medios de comunicación, particularmente la radio y televisión; $b$ ) la prohibición a la contratación de propaganda político-electoral; c) las restricciones al contenido de la propaganda electoral; $d$ ) las restricciones al contenido y ámbito temporal de la propaganda gubernamental; $e$ ) el régimen de sanciones frente a las infracciones cometidas en la materia; $f$ ) el reconocimiento y garantía del derecho de réplica, y $g$ ) la realización de debates entre candidatos. ${ }^{11}$

Dicha intervención se justifica en el relevante papel que el principio constitucional de equidad ha adquirido al interior de la función electoral de nuestro país, que impone el establecimiento de reglas precisas para eliminar el factor oneroso en el acceso a los medios de comuni-

11 En torno a las premisas del modelo, acúdase a Astudillo, César, "El nuevo sistema...", cit. pp. 131 y ss. 
Esta revista forma parte del acervo de la Biblioteca Jurídica Virtual del Instituto de Investigaciones Jurídicas de la UNAM

cación con el objeto de generar paridad de condiciones en la competencia política.

Por ende, contrario a lo que aducen sus detractores, la introducción de un nuevo modelo de comunicación político-electoral no "vulneró" ni "atentó" contra la libertad de expresión, sino que la moduló, o para ser más precisos, la delimitó. La diferencia no es menor. No es lo mismo transgredir, quebrantar o violar un derecho fundamental que determinar sus contornos jurídicos, es decir, proceder a fijar la extensión y los alcances que puede tener. En este específico contexto, la delimitación se produjo mediante la incorporación de las premisas del modelo de comunicación política asentado en gran parte de las democracias consolidadas europeas, con la finalidad de eliminar el acceso oneroso de los partidos a la radio y televisión, otorgarles la prerrogativa exclusiva de difundir propaganda político-electoral e impedir que ninguna persona física o jurídica pueda contratar espacios de publicidad electoral. ${ }^{12}$

\section{Deficiencias institucionales que no favorecen la fluidez de la libertad de expresión en su manifestación político-electoral}

Dado que el objetivo del modelo de comunicación político-electoral es favorecer el intercambio libre y plural de ideas de todos los sujetos que interactúan en el espacio público mediante la intermediación de los medios de comunicación, es necesario apuntar aquellas deficiencias del diseño institucional que no favorecen una mayor fluidez en la manifestación de las ideas ni su oportuna socialización en el ámbito electoral. ${ }^{13}$

\section{A. La predeterminación de un formato único. La carencia de alternativas a una comunicación fluida}

La comunicación político-electoral puede adquirir diversos formatos y contenidos; unos permiten una mayor fluidez y un más profundo

12 Para profundizar en este aspecto, acúdase a Astudillo, César, "La libertad de expresión..., cit., pp. 16 y ss.

13 Los temas tratados a continuación se exponen de manera más amplia en ibidem, pp. 23 y ss. 
Esta revista forma parte del acervo de la Biblioteca Jurídica Virtual del Instituto de Investigaciones Jurídicas de la UNAM

contenido informativo como los debates, las entrevistas y conferencias de prensa, mientras que otros se dirigen a enviar breves mensajes y propuestas - como los spots y la publicidad electoral- bajo una construcción persuasiva que une la dimensión verbal con la visual, pero que por su brevedad y unilateralidad, en tanto pensados y diseñados exclusivamente por los partidos políticos, disminuyen la riqueza de su contenido.

Por paradójico que parezca, la totalidad del tiempo que el Estado confiere a los partidos políticos y las instituciones electorales, en vez de ser adecuadamente utilizado dentro de un abanico de formatos para la comunicación quedó drásticamente reducido a un formato casi único que terminó por repartirlo en spots de breve duración. En la decisión de privilegiar la fluidez o la predeterminación del contenido de los mensajes políticos, el legislador optó por esta última posibilidad. ${ }^{14}$

El formato elegido ha limitado las potencialidades de la comunicación política e institucional al preferir píldoras de 20 y 30 segundos, de escaso valor informativo sobre modalidades que auspician un flujo más libre y flexible de información político-electoral, de ideas, posturas, críticas, posiciones y propuestas políticas.

Los programas mensuales de cinco minutos al que tienen derecho los partidos políticos, si bien representan una modalidad distinta en virtud de su duración, no generan mayor influencia electoral al transmitirse al margen de los procesos comiciales; además, el horario en el que se divulgan termina por limitar la capacidad de influencia que pudieran tener, lo cual redunda en que los partidos dejen de poner la atención en su producción y contenido, volviéndolos poco atractivos para el ciudadano.

La incorporación de los debates presidenciales representa un nuevo formato comunicacional necesario para la formación de la opinión pública y la consolidación de una sociedad democrática. El formato permite que los candidatos puedan difundir sus ideas, propuestas $y$ programas políticos en un contexto deliberativo que fomenta el intercambio y la confrontación de opiniones y puntos de vista, la crítica de las mismas y el contraste entre candidatos. Sin embargo, el influjo que tienen los representantes de los partidos políticos y sus candidatos en la determinación de los lineamientos, criterios y bases a los que

14 Woldenberg, José, Comunicación política, medios y elecciones, México, AMEDI, abril 2011. 
Esta revista forma parte del acervo de la Biblioteca Jurídica Virtual del Instituto de Investigaciones Jurídicas de la UNAM

habrán de sujetarse, han terminado por modular la riqueza de estos ejercicios comunicativos y por anteponer la rigidez y solemnidad del formato elegido ante la dificultad de armonizar las diferentes estrategias e intereses políticos de los contendientes.

De conformidad con lo expuesto, resulta inexorable repensar el formato "casi único" prefigurado por el modelo de comunicación político-electoral y madurar formatos que posibiliten una comunicación más fluida con la intención de enriquecer la calidad de la competencia política, que doten de mayor dinamismo y oportunidad política al desarrollo de las campañas, aproximen un mayor volumen de información al ciudadano y mantengan la atención del electorado en un contexto en el que la constante repetición de dichos mensajes en la dinámica de la campaña produce una saturación audiovisual que en el corto y mediano plazo, puede generar repercusiones negativas. ${ }^{15}$

B. La rigidez de la regulación. La ausencia de la flexibilidad necesaria

Al elevar las premisas del nuevo modelo de comunicación política a rango constitucional se produjo un doble efecto contrario, con consecuencias particulares para la permanencia, estabilidad e, incluso, aceptabilidad del modelo, pero también para su extrema rigidez y la dificultad de su cambio, acomodo y adaptación.

La cobertura constitucional de reglas que evidentemente carecen de la relevancia para ubicarse en tan privilegiado espacio normativo, sólo es explicable como un acto de blindaje y de redefinición de la relación entre los poderes del Estado y los poderes mediáticos. ${ }^{16}$ La necesidad de proteger desde la más alta norma jurídica al modelo condujo a que los legisladores depositaran escrupulosamente en la Constitución mexicana el tiempo que el IFE debe administrar a partir de criterios como el "periodo", la "duración", el "formato", los "sujetos beneficiarios”, el "ámbito de difusión”, lo cual ha terminado por apartarlo de la flexibilidad necesaria para utilizar los tiempos de Estado en esquemas

15 Véase Juárez Gámiz, Julio y Brambila, José Antonio, “Contenido y estructura de la publicidad política televisiva en el proceso electoral federal 2012", Revista Mexicana de Derecho Electoral, núm. 3, enero-junio 2013, pp. 218 y ss.

16 Córdova Vianello, Lorenzo, "Las razones y el sentido de la reforma”, en id. y Salazar Ugarte, Pedro, Estudios sobre la reforma electoral 2007. Hacia un nuevo modelo, México, TEPJF, 2008, pp. 49 y ss. 
Esta revista forma parte del acervo de la Biblioteca Jurídica Virtual del Instituto de Investigaciones Jurídicas de la UNAM

menos estrictos y con mayor capacidad de adaptación a las distintas necesidades de la comunicación política.

En este sentido, es necesario reflexionar sobre la manera de introducir esquemas de flexibilización que sin perder el blindaje constitucional que hoy caracteriza al modelo, posibiliten un uso menos rígido de los tiempos del Estado para escapar de la tiranía del formato casi único al que ya se ha hecho referencia. Paradójicamente, el haber constitucionalizado el modelo conduce inexorablemente a que la apertura, flexibilización o introducción de nuevos formatos comunicativos pase por una nueva reforma constitucional, ya que su introducción en la legislación ordinaria derivaría con seguridad en impugnaciones que constatarían la vulnerabilidad de todo aquello que se encuentra al margen de la Constitución mexicana.

\section{La unidireccionalidad del modelo. El ciudadano como sujeto pasivo del proceso comunicativo}

La comunicación política es en esencia bidireccional, derivado de su capacidad para abrir canales a la interacción directa entre los sujetos participantes. Si bien esta cualidad no está siempre presente en la comunicación que se difunde a través de los medios clásicos, como la radio y la televisión, importante es advertir que la irrupción de las plataformas de Internet y de las redes sociales han venido a cambiar el rostro de los usos comunicativos, obligando a todos los medios de difusión a ajustarse a nuevas modalidades caracterizadas por la apertura de vínculos dialécticos entre sus participantes.

Como consecuencia del punto de inflexión que ha traído consigo la revolución tecnológica, asistimos a la metamorfosis de una modalidad de campaña eminentemente contemplativa, en donde el ciudadano se reducía al papel de receptor de los mensajes políticos, a un tipo de campañas "replicantes" o "interpelativas" en las que el ciudadano se erige como centro de mensajes y demandas directas a los candidatos, y en el cual los medios pierden cada vez más su capacidad de servir como agentes de intermediación, filtro y encauzamiento de las vías de acceso al conocimiento de los asuntos públicos. ${ }^{17}$

17 En torno a las características de este tipo de comunicación, campaña e incluso, de la "democracia replicante", acúdase a Dader, José Luis, "La ciberdemocracia posible. Reflexión prospectiva a partir de la experiencia en España”, CIC Cuadernos de Información y Comunicación, núm. 6, Madrid, UCM, 2001, pp. 178 y ss. 
Esta revista forma parte del acervo de la Biblioteca Jurídica Virtual del Instituto de Investigaciones Jurídicas de la UNAM

El modelo instaurado en la reforma constitucional-electoral de 2007, basado preponderantemente en el formato del spot, sigue anclado en una visión vertical de la comunicación político-electoral que no favorece un proceso comunicativo abierto, fluido y dialéctico, ni la instauración de campañas deliberativas o replicantes, mucho menos flexibles y espontáneas en donde la difusión de sus mensajes puedan ser ajustados mediante criterios de oportunidad política.

De cara a la reforma del modelo es necesario replantear esta premisa para generar un modelo de comunicación político-electoral más horizontal, en donde el ciudadano se considere no solamente receptor, sino agente activo del proceso comunicativo, con capacidad para generar información, debatir, replicar y participar decididamente en la deliberación política, y movilizarse al interior de las campañas electorales.

\section{La incompletitud del modelo. La omisión de sujetos que deben tener voz en el proceso comunicativo}

Todo modelo de comunicación político-electoral necesita dar voz a los distintos sujetos del sistema político, sean estos los poderes públicos, los partidos políticos o los ciudadanos. En función de ello, está llamado a garantizar que quienes participan en el espacio deliberativo tengan condiciones razonablemente equitativas de hacer llegar sus mensajes hacia el ciudadano-elector.

Con motivo de la reforma política de agosto de 2012 y la incorporación de las candidaturas independientes al sistema constitucional mexicano, el modelo de comunicación político-electoral demostró uno más de sus inconvenientes actuales: su falta de integralidad. En efecto, no fue reformado para permitir que los ciudadanos postulados en ejercicio de sus derechos de participación política, sin el auspicio de partido político alguno, tuvieran acceso a los tiempos del Estado en la radio y la televisión, manteniéndose rígidamente asentado en el monopolio de la participación política de los partidos.

Lo apenas señalado incorpora un profundo sentido de inequidad al afectar la paridad de condiciones en la competencia política, por la desventaja que infiere a los candidatos independientes frente a los partidos políticos, en detrimento de la socialización de información de todos los sujetos políticamente relevantes, en clara contravención del derecho fundamental de acceder en condiciones generales de igualdad a las funciones públicas del país. 
Esta revista forma parte del acervo de la Biblioteca Jurídica Virtual del Instituto de Investigaciones Jurídicas de la UNAM

El modelo evidencia por tanto un rasgo de exclusión que debe ser puntualmente atendido para incorporar esta nueva modalidad de mensajes al circuito de la comunicación política. Mientras impida el flujo de información entre todos los actores relevantes del escenario público no podrá considerarse integral, abierto, plural y omnicomprensivo.

\section{E. La ausencia del sentido de igualdad. La discriminación en los criterios de distribución}

Un modelo de comunicación político-electoral asentado en la máxima de la equidad está obligado a otorgar posibilidades de difusión de mensajes de contenido político razonablemente proporcionales a todos quienes compiten por el sufragio ciudadano. Privilegiar las voces de unos en detrimento de otros, abrir canales de comunicación exclusivamente a ciertos sujetos y cerrárselos a otros, o discriminar el acceso a medios de comunicación bajo la premisa de que ciertos cargos o mensajes son más relevantes que otros, constituyen decisiones que pueden justificarse bajo ciertas condiciones, pero que en determinados contextos resultan altamente negativas y reprochables.

La distribución de los tiempos de Estado en radio y televisión actualmente vigente confiere características de inequidad al modelo de comunicación político-electoral en tanto alimenta un trato diferenciado bajo el criterio del "tipo de elección" federal o estatal de que se trate. En un entorno democrático el ciudadano debe contar con iguales oportunidades de recibir información, tanto de las elecciones federales como de las estatales, porque en ambos casos necesita estar en condiciones de ejercer el voto de manera informada y razonada.

Contrario a esta premisa, el esquema de distribución se guió por elementos cualitativos y no cuantitativos, dado que son muchos más los puestos de representación popular que se eligen en el ámbito de los estados y el Distrito Federal, que los de la federación; sin embargo, la presidencial es la elección de mayor significación política y como tal suele acaparar un mayor grado de atención mediática que encuentra su correspondiente en las normas del modelo que otorgan mayores tiempos a las campañas federales. ${ }^{18}$

18 Los tiempos que corresponden a las elecciones federales y estatales se explican en IFE, Administración del tiempo del Estado en radio y televisión para fines electorales, Mé- 
Esta revista forma parte del acervo de la Biblioteca Jurídica Virtual del Instituto de Investigaciones Jurídicas de la UNAM

El número de cargos de elección popular en los estados de la República, así como la reciente reforma a favor de las candidaturas independientes obliga a tener en cuenta el criterio cuantitativo en la redefinición de tiempos entre las campañas federales y estatales.

\section{Libertad de expresión y el derecho a la información en los documentos básicos de los partidos políticos}

\section{Primera parte: presupuestos metodológicos y teóricos}

De la consulta de los documentos básicos correspondientes a cada uno de los partidos se desprende que todos ellos formularon múltiples planteamientos en relación con ocho de los nueve temas relacionados con la libertad de expresión y al derecho a la información, resultando pertinente hacer notar que en cuanto al tema de derecho de réplica, solo un partido formuló un planteamiento al respecto y éste fue en términos por demás escuetos.

\begin{tabular}{|l|c|c|c|c|c|c|c|}
\hline \multicolumn{8}{|c|}{ Sistematización de propuestas por tema de cada partido político } \\
\hline \multicolumn{1}{|c|}{ TEMA } & PAN & PRI & PRD & PT & PVEM & PANAL & PMC \\
\hline 1. Libertad de Expresión & 3 & 5 & 5 & 1 & 1 & 0 & 1 \\
\hline 2. Derecho a la Información & 4 & 11 & 4 & 3 & 8 & 1 & 2 \\
\hline 3. Libertad de Prensa & 2 & 0 & 1 & 0 & 0 & 2 & 0 \\
\hline 4. Derecho de Réplica & 0 & 0 & 1 & 0 & 0 & 0 & 0 \\
\hline $\begin{array}{l}\text { 5. Derechos sucedáneos a } \\
\text { la Libertad de Expresión }\end{array}$ & 0 & 0 & 1 & 1 & 4 & 5 & 1 \\
\hline $\begin{array}{l}\text { 6. Libertad de Expresión } \\
\text { en Radio y TV }\end{array}$ & 1 & 2 & 4 & 1 & 2 & 0 & 0 \\
\hline 7. Rendición de Cuentas & 1 & 1 & 0 & 0 & 2 & 0 & 2 \\
\hline $\begin{array}{l}\text { 8. Derechos reconocidos a } \\
\text { los militantes y afiliados }\end{array}$ & 1 & 2 & 1 & 6 & 2 & 1 & 2 \\
\hline 9. Redes sociales & 1 & 0 & 0 & 0 & 0 & 0 & 2 \\
\hline
\end{tabular}

Del centenar de planteamientos y propuestas formuladas por los partidos políticos, las más consistentes se explican en los siguientes apartados. 
Esta revista forma parte del acervo de la Biblioteca Jurídica Virtual del Instituto de Investigaciones Jurídicas de la UNAM

2. Planteamientos más consistentes en relación con la libertad de expresión

El Partido Acción Nacional (PAN), en su Declaración de Principios sostiene que "la libertad de cada persona ha de coexistir creativa y solidariamente con la libertad de los demás. Los medios deben estar adecuados al fin. Un fin éticamente valioso no justifica la utilización de medios éticamente inadmisibles."

En su Programa de Acción, en el punto 80 sustenta que

la libertad de expresión y el derecho a la información deben ser tutelados y regulados bajo los principios de interés público, apertura, salvaguarda a la vida privada y respeto al derecho de réplica. La ley debe reformarse para que el régimen de concesiones sea transparente, para fijar criterios en el uso de los tiempos oficiales del Estado y para crear un órgano autónomo que vigile y defienda estos preceptos.

En cuanto a su Plataforma Electoral, en el apartado intitulado "México Sólido", afirma que el partido promoverá los mecanismos pertinentes que garanticen el ejercicio de la libertad de expresión y el derecho a la información, en un marco de libertad y responsabilidad social compartida.

En ese sentido, en los documentos básicos del Partido Revolucionario Institucional (PRI), sólo figura un planteamiento sobre el tema, que se encuentra en el numeral 28 de la Declaración de Principios y advierte que "la libertad de expresión es un valor fundamental de la convivencia social".

En tanto que en el Programa de Acción del Partido de la Revolución Democrática (PRD), afirma en el punto 13 su compromiso para impulsar una reforma constitucional que garantice la libre manifestación de las ideas sin reproducir estereotipos que denigren la imagen de las personas por cualquier motivo discriminatorio, y también para que se estimule entre los medios de comunicación la promoción, igualdad de género, no discriminación, no violencia en contra de las mujeres y respeto a las diferencias, en el marco de la libertad de prensa.

En el numeral 73, relativo al derecho a la información, se expresa la propuesta de establecer en la legislación que la libertad de expresión implica el derecho a recibir y a emitir información y opiniones sin 
Esta revista forma parte del acervo de la Biblioteca Jurídica Virtual del Instituto de Investigaciones Jurídicas de la UNAM

censura, a través de los medios de comunicación. Asimismo, se distingue el significado que tiene el concepto de libertad de expresión para las personas, para quienes significa, básicamente, tener la posibilidad de acceder a los medios para poder expresarse y para los concesionarios, quienes a menudo la entienden como reducción de la normatividad o como libertad de programación.

En el punto 100, se pronuncia para que las autoridades no puedan prohibir o impedir formas de vestir o expresiones artísticas bajo consideraciones morales o religiosas correspondientes a un individuo, grupo de individuos o cualquier religión.

\section{Planteamientos más consistentes en relación con el derecho a la información}

El PAN, en el punto 80 de su Programa de Acción señala que la libertad de expresión y el derecho a la información deben ser tutelados y regulados bajo los principios de interés público, de apertura, de salvaguarda a la vida privada y de respeto al derecho de réplica. Así, la ley debe reformarse para que el régimen de concesiones sea transparente, para fijar criterios en el uso de los tiempos oficiales del Estado y para crear un órgano autónomo que defienda estos preceptos.

En el numeral 100, considera que el acceso a la información del gobierno debe ser una garantía de los ciudadanos en los órdenes federal, estatal y municipal, incluyendo los poderes Legislativo y Judicial y a todo aquél que reciba y ejerza recursos públicos. De manera que la transparencia requiere de leyes e instituciones públicas que le aseguren al ciudadano que la información de los gobiernos en todos sus órdenes es un bien público y un derecho.

En el apartado 1o. "México Próspero" de su Plataforma Electoral, comenta que seguirá

empujando... la modernización regulatoria de las comunicaciones, la convergencia digital y la ampliación de la carretera de la información, para que todas la empresas y todos los mexicanos, puedan disfrutar de los beneficios que ofrecen las tecnologías de la información y las comunicaciones.

Mientras que en el apartado sexto, "México Equitativo", punto 16, sostiene que utilizará las tecnologías de la información para ampliar 
Esta revista forma parte del acervo de la Biblioteca Jurídica Virtual del Instituto de Investigaciones Jurídicas de la UNAM

la educación a distancia y generar contenidos complementarios para los programas educativos, extendiendo la conectividad en las escuelas para un mayor aprovechamiento del alumnado y cuerpo docente.

$\mathrm{Al}$ respecto el PRI, en su Programa de Acción contempla una serie de pronunciamientos sobre el tema, de manera que en los numerales 38 y 39 señala que al haberse concretado las reformas a la Constitución mexicana y una parte de las leyes reglamentarias en materia electoral (2007), el partido se compromete a realizar las modificaciones a otros ordenamientos todavía pendientes de ser discutidos y aprobados, que permitan complementar el conjunto de estas disposiciones jurídicas, como destacadamente es el caso de la Ley Federal de Radio y Televisión, para que se puedan hacer efectivas las sanciones que el IFE determine por el incumplimiento de las nuevas disposiciones electorales; de igual forma es de mencionar la reforma a la Ley Federal de Transparencia y Acceso a la Información Pública Gubernamental...

En el apartado II de su Plataforma Electoral, sostiene que una sociedad democrática y funcional se construye con el debate público e informado, es así que el gobierno tiene el deber de socializar la información pública, mejorar su calidad y propiciar las bases de veracidad para la evaluación, fiscalización y rendición de cuentas de los asuntos públicos, para lograrlo, es indispensable que se garantice el acceso a la información de la ciudadanía, para que sean informados no sólo del ejercicio de los recursos, sino también para conocer las causas de la toma de decisiones e integración de proyectos gubernamentales, y de sus resultados.

En la Plataforma Electoral el PRI sintetiza su propuesta sobre el tema en varios puntos, $\mathrm{y}$ en esos términos:

a) Otorga mayores atribuciones para el IFAI a efecto de que en un marco de autonomía tenga facultades para:

- Vigilar el cumplimiento y resolver sobre posibles negativas de acceso a la información de los poderes Legislativo y Judicial.

- Imponer sanciones por incumplimiento a sus resoluciones.

- Ordenar a los sujetos obligados a que generen información en el caso de que sea declarada previamente como inexistente.

- Alertar a la Auditoría Superior de la Federación (ASF) sobre las áreas de opacidad que detecte por negación, presentación incompleta o declaración de inexistencia de la información pública. 
Esta revista forma parte del acervo de la Biblioteca Jurídica Virtual del Instituto de Investigaciones Jurídicas de la UNAM

b) Fortalece las áreas de información del Poder Ejecutivo, Legislativo y Judicial, capacitando a las personas encargadas de éstas para establecer el dominio público de la información que está en manos del Estado.

c) Establece un sistema de rendición de cuentas que combata la corrupción, evite la impunidad y promueva la transparencia de las instituciones de gobierno, involucrando a la sociedad.

d) Impulsa un Sistema Nacional de Fiscalización, con la finalidad de establecer parámetros uniformes en el sistema de rendición de cuentas, en lo relativo al gasto público federal.

e) Aprovecha el potencial de las tecnologías de la información y la comunicación para ampliar las vías de acceso a la información pública, con base en sus capacidades y cualidades.

En ésta temática, el PRD, señala en el numeral 14 intitulado "Derecho a la Información", correspondiente a su Programa de Acción, que "el ejercicio de la ciudadanía requiere de información veraz, oportuna, comprobable y no discriminatoria, por lo que las y los mexicanos tendrán derecho a recibir información de los asuntos públicos, el que estará garantizado por el Estado y por una legislación eficaz", de manera que el Estado estará obligado a informar públicamente sobre los aspectos principales de su desempeño, y en ese sentido, para que el derecho a la información sea ejercido de manera eficiente, no bastará con que las autoridades u organismos públicos independientes proporcionen información a quien la solicita, sino que ésta deberá ser presentada de forma tal que permita ser analizada y procesada fácilmente por el solicitante. Se adhieren a esto, los numerales 73 y 100 señalados supra.

\section{Libertad de expresión en el ámbito electoral y sus operadores jurídicos}

El tema de la libertad de expresión en cuanto a su contenido y en tanto derecho público subjetivo se entiende en un triple sentido, así: buscar, recibir y difundir informaciones e ideas de toda índole, en lo que hace al ámbito electoral y sus operadores jurídicos, se presenta como multidimensional, a saber: desde un punto de vista filosófico o de la filosofía política, en lo que se refiere al fundamento de los derechos, 
Esta revista forma parte del acervo de la Biblioteca Jurídica Virtual del Instituto de Investigaciones Jurídicas de la UNAM

ya en tanto categoría de humanos, bien en cuanto fundamentales; desde el derecho positivo, por lo que hace a las normas jurídicas y los precedentes relacionados con éstas; más aún, la libertad de expresión en la materia de mérito en este estudio, que desde luego es la electoral, es dable ser analizada desde la sociología o la ciencia política, la importancia de cada una de las esferas que se constituyen en torno al derecho nos obliga a excluirlas sin obviar el grado de incidencia que tienen en la materia esencialmente política en sentido electoral.

En virtud de la naturaleza del tema, hemos considerado necesario incluir la teoría del operador jurídico, para entender la toma de decisiones públicas en los ámbitos sociales, administrativos y jurisdiccionales.

Por lo que hace a la libertad de expresión en su sentido instrumental o adjetiva, id. est., en tanto garantía, la ciencia y la teoría política la han ligado a la emergencia y/o transformación de los regímenes políticos, autocráticos o democráticos, en tanto hace posible la construcción del andamiaje electivo y la renovación periódica de los titulares de los órganos de potestad estatal, y la plena concreción del estándar legitimador ${ }^{19}$ (Herrschaft), legal-racional diría Weber, por excelencia de las democracias liberales, a saber: el principio democrático y el pluralismo.

En el hilo argumentativo del presente trabajo se encontrará, en principio, un análisis sobre el binomio derechos humanos y libertad de expresión, metodológicamente presupuestos necesarios para el análisis de la libertad de expresión en el ámbito electoral mexicano y, en segundo término, las implicaciones de este proceso en la operación jurídica, concretada por los órganos electorales federales (administrativo y jurisdiccional), seleccionando como caso de estudio el expediente SUP-JIN-359/2012, al que consideramos caso paradigmático.

\section{Los derechos humanos y sus operadores jurídicos}

Los derechos humanos sólo son asibles intelectivamente y en su práctica progresiva y expansiva bajo la condición necesaria que se positiven y garanticen en un tipo de régimen y de Estado, así como a una

19 Bobbio, Norberto, El tiempo de los derechos, Madrid, Sistema, 1991, pp. 98 y 101; por lo que hace a los fundamentos sociopolíticos, Véase id., Estado, gobierno y sociedad, México, FCE, 1989, pp. 117-127. 
Esta revista forma parte del acervo de la Biblioteca Jurídica Virtual del Instituto de Investigaciones Jurídicas de la UNAM

intensa tendencia: el democrático y el constitucional de derecho, y su creciente internacionalización y especificación, ${ }^{20}$ cuyos fundamentos teórico ${ }^{21}$ son, a saber: $a$ ) una idea del ser humano y de la construcción de la ciudadanía; $b$ ) una forma de organización del poder que implica la existencia y buen funcionamiento del Estado; c) una ciudadanía plena y activa, en las esferas de lo civil, lo político y lo social; ${ }^{22} d$ ) una experiencia histórica particular en la región, que debe ser entendida y evaluada en su especificidad, ye) un régimen electoral como elemento fundamental, pero no se reduce a las elecciones, ${ }^{23}$ hace posible la realización de estos derechos humanos.

La democracia, en cualesquiera de sus adjetivaciones, requiere de presupuestos para su operación en la toma de decisiones informadas, críticas, propositivas y, por tanto, intersubjetivas, es en este sentido que cobra importancia la participación de la ciudadanía y de la sociedad en general.

La conformación y consolidación de los derechos humanos en sus dimensiones filosófica, histórica, positiva e internacional, evidencia el iter evolutivo de su comprensión cabal, cuyo sustrato insoslayable se remonta a la emergencia del pensamiento liberal pero, sobre todo, a la razón práctica de éste, en el siglo XVIII.

La segunda posguerra se erige en clave de bóveda para el reconocimiento de los derechos humanos y su expansividad, 1948 data significativa en el reconocimiento internacional de aquéllos y, específicamente, de la libertad de expresión reconocida en el artículo 19 de la Declaración Universal de los Derechos Humanos, desde entonces hasta la época actual el sucesivo reconocimiento de la bilateralidad del derecho.

20 Bobbio, Norberto, El tiempo de los derechos... op.cit., p. 101.

${ }_{21}$ Bobbio, Norberto, Fundamento y futuro de la democracia, Valparaiso, EDEVAL, 1990, pp. 11-30.

22 Hernández, María del Pilar, "Institucionalidad electoral y derechos políticos de las mujeres", Revista Mexicana de Derecho Electoral, núm. 3, México, UNAM, Instituto de Investigaciones Jurídicas, enero-junio 2013.

23 Programa de las Naciones Unidas para el Desarrollo, La democracia en América Latina. Hacía una democracia de ciudadanos y ciudadanas, Argentina, Aguilar-AlteaTaurus-Alfaguara, 2004, p. 24. (el documento aborda los casos de Argentina, Bolivia, Brasil, Chile, Colombia, Costa Rica, Ecuador, El Salvador, Guatemala, Honduras, México, Nicaragua, Panamá, Paraguay, Perú, República Dominicana, Uruguay y Venezuela). 
Esta revista forma parte del acervo de la Biblioteca Jurídica Virtual del Instituto de Investigaciones Jurídicas de la UNAM

Implicando tal bilateralidad, en tanto materialización del pensamiento, el simbolismo, la expresión verbal y, desde luego, la expresión escrita, pero al mismo tiempo el acceso a la información.

El tránsito que va desde la erección misma de la libertad como núcleo irreductible y límite categórico al Estado, hasta la libertad a través o por medio del Estado, encuentra hoy su más clara resignificación en aquellos derechos que ya a principios del siglo XX Jellinek denominara iura activae civitatis, así, los derechos políticos son “... un complemento natural de los derechos de libertad y de los derechos civiles..." 24

La libertad de expresión en materia política-electoral continúa ubicada en el esquema de la libertad extensa, al menos en nuestro país, que se concreta a través y por medio del Estado, así lo demuestra su positivación en los artículos 6o. y 7o. de la Constitución mexicana, adquiriendo límites constitucionales precisos - prohibiciones- para los sujetos de la relación, para el (los) ciudadano(s), para el propio Estado interdictando la censura - directa o indirecta, previa o posterior-, so riesgo de afectar el núcleo esencial del derecho -wesensgehalt_ vaciándolo - aushöhlen-. ${ }^{25}$

La libertad de expresión así reconocida, se erige en requisito sine qua non - no suficiente ni exclusivo- y presupuesto necesario de los regímenes democráticos o, en otro sentido, la libertad de expresión concretada en el espacio público y erigida en opinión pública ${ }^{26}$ se convierte en humus fértil para el tránsito del Estado liberal al Estado liberal democrático; la libertad de expresión, en principio y como última ratio, puede ser manipulada y deformada pero, inopinadamente, constituye el eje de la cohesión social, de la construcción y legitimación (o deslegitimación) política.

24 Bobbio, Norberto, Liberalismo y ... op. cit., p. 47.

25 Hernández, María del Pilar, "Los límites al control de constitucionalidad", en Astudillo, César y Córdova Vianello, Lorenzo, Reforma y control de la Constitución. Implicaciones y límites, México, UNAM, Instituto de Investigaciones Jurídicas, 2011, p. 145.

26 Habermas, Jürgen, Historia y crítica de la opinión pública, La transformación estructural de la vida pública, Barcelona, G. Gili, 1981; en el mismo sentido: Arendt, Hanna, La condición humana, Barcelona, Paidós, 1993; Lazarsfeld, Paul y Katz, Elihu, La influencia personal, Barcelona, Ed. Hispano Europea, 1979; Berelson, Bernard y Janowitz, M., Public Opinion and Communication, Glencoe, Ill, 2a. ed., Nueva York, The Free Press, 1966; Steinberg, Ch. S., Los medios de comunicación social, México, Editorial Roble, 1969; Wright Mills, Charles, La élite del poder, México, Fondo de Cultura Económica, 1975; Manheim, Ernst, La opinión pública. Madrid, Ed. Rev. Derecho Privado, 1936. 
Esta revista forma parte del acervo de la Biblioteca Jurídica Virtual del Instituto de Investigaciones Jurídicas de la UNAM

Tales ideas han sido cabalmente recogidas por el contexto de las naciones, trátese de los diversos sistemas constitucionales, ya en los sistemas internacional y regionales de derechos humanos (Europeo e Interamericano, esencialmente), cuya casuística ha permitido la formación de un corpus jurisprudencial que posibilita la apreciación meridiana de la libertad de expresión, su eventual categorización atendiendo al qué se expresa - ideas, informaciones, opiniones o creencias personales- y por tanto su tutela en términos del interés público que revistan; quién las expresa, y consecuentemente, el grado de mayor tolerancia en tratándose de quienes aspiran a un cargo o ya lo desempeñan - electivos o de designación- por estar sujetos a un escrutinio mayor por parte de la sociedad, en dónde se limita —sólo son admisibles por excepción y bajo condición que estén previstas en ley de manera clara y precisa, así como dirigidas al logro de objetivos imperiosos reconocidos por la Convención y que sean necesarias en una sociedad democrática-. ${ }^{27}$

En México la reforma a la Constitución mexicana en materia de derechos humanos, publicada en el DOF del 10 de junio de 2011, obliga a los operadores jurídicos a superar la visión "formalista" sustentada en un enfoque "normativista" y sustituirlo por un enfoque sustentado en el ser humano, en donde se consideran derechos públicos subjetivos lo más favorables al individuo y la protección del derecho humano, vía el sistema interamericano de derechos humanos a través de un denominado control de convencionalidad, ${ }^{28}$ esencialmente por la incorporación de un principio como el pro homine o pro persona.

Pero la pregunta es ¿quiénes actualizan, redimensionan o dotan de contenido a los derechos? Cabalmente los operadores jurídicos.

Entendemos por "operador jurídico", en la acepción originaria que le diera por primera vez Renato Treves, aquellos que desde el ámbito estatal o privado se vinculan con la aplicación y/o interpretación del derecho, ${ }^{29}$ el caso del orden jurídico mexicano, a saber, IFE y Tribunal

27 Relatoría especial para la libertad de expresión, Marco Jurídico Interamericano sobre el derecho a la libertad de expresión, OEA/CIDH, 2010, p. 11.

28 Ver la resolución de los casos resueltos por ese tribunal en los que se ha urdido el concepto: Myrna Mack Chang vs. Guatemala, sentenciado el 25 de noviembre de 2003, particularmente en el párrafo 27 del voto concurrente razonado del juez Sergio García Ramírez; Caso Tibi vs. Ecuador del 4 de septiembre de 2004, párrafo 3 y 4 del voto concurrente razonado del mismo juez.

29 Treves, Renato, El juez y la sociedad, Madrid, Cuadernos para el Diálogo, 1974. En- 
Esta revista forma parte del acervo de la Biblioteca Jurídica Virtual del Instituto de Investigaciones Jurídicas de la UNAM

Electoral del Poder Judicial de la Federación (TEPJF), sin obviar el rol que como órgano de control de constitucionalidad desarrolla el tribunal pleno de la Suprema Corte de Justicia de la Nación (SCJN).

Cuál es el estado de la cuestión atendiendo a la labor de la Sala Superior del TEPJF. Nos parece que es por demás encomiable y conteste a la labor de la Corte Interamericana de Derechos Humanos (Corte IDH), aunque en ocasiones resulta regresiva su interpretación.

Por lo que hace a los límites al derecho de mérito, si bien avanza en 2008 en el asunto "Libertad de expresión e información, su maximización en el contexto del debate político" donde destaca que el ejercicio de libertad de expresión no es absoluto, encuentra límites en la seguridad nacional, orden público o salud pública, al igual que otros de carácter subjetivo o intrínseco de la persona, vinculados principalmente con la dignidad o la reputación. En lo atinente al debate político, el ejercicio de tales prerrogativas ensancha el margen de tolerancia frente a juicios valorativos, apreciaciones o aseveraciones vertidas en esas confrontaciones, cuando se actualiza en el entorno de temas de interés público en una sociedad democrática. Todo lo contrario sucede en el caso "La verdad no divide" - SUP-RAP 256/2012 - ya que echa por tierra el avance.

La utilización de propaganda negativa en campañas electorales presenta una serie de cuestiones relevantes sobre el dilema entre libertad de expresión y calidad de democracia.

Al decir de Calvert “... los anuncios políticos negativos televisados plantean el más serio problema de nuestra democracia autogobernada. No son discurso político, sino discurso invalidante de la democracia". ${ }^{30}$

Existen argumentos a favor y en contra de la propaganda negativa $\mathrm{y}$, en última instancia, podría aconsejar algún tipo de - mínima- regulación de este tipo de discurso. El argumento se basa en la maximización del derecho en el contexto del debate político.

No obstante que el contenido del referido asunto es casi similar en términos de degradación a la persona de Peña Nieto, candidato del PRI, en el caso "Peña" - SUP-RAP 319/2012 - considera que sí se concreta la denigración y la calumnia en la persona del candidato, lo

tre otros operadores el Maestro cita notarios, registradores, servicios de policía, testigos, jurados, mediadores, administradores, inter alia.

30 Calvert, Clay, "When First Amendment principles collide: Negative political advertising \& the demobilization of democratic self-governance", Loy Law Review, núm. 30, L.A., Loyola Marymount University and Loyola Law School, 1997, p. 1528. 
Esta revista forma parte del acervo de la Biblioteca Jurídica Virtual del Instituto de Investigaciones Jurídicas de la UNAM

que constituye una "connotación oprobiosa" para los integrantes de dicho instituto político de cara al electorado, y en consecuencia no admisibles en una contienda electoral.

Más allá que existen parámetros claros, constitucionales y legales, pareciera olvidar la Sala Superior que, conforme a Calvert: ${ }^{31}$

1) El debate racional y deliberativo pierde valor por anuncios negativos, superficiales, de 30 segundos que proveen poco contexto e información sustantiva.

2) El debate racional y deliberativo pierde valor por anuncios negativos, de 30 segundos, superficiales que apelan más a emociones que a la razón.

3) El debate racional y deliberativo pierde valor por anuncios negativos, de 30 segundos, superficiales que proveen información falsa y engañosa.

4) Participación en el autogobierno democrático, como refleja la participación de los votantes, es reducido por anuncios negativos, de 30 segundos, superficiales.

Por lo que hace a la actuación del IFE, ha menester indicar las grandes tensiones y en otras las coincidencias que se pusieron en evidencia en el proceso electoral federal de 2012, de forma por demás focalizada en los candidatos a la Presidencia de la República, como es obvio, y la Sala Superior del TEPJF, temáticamente sobresalen:

- Libertad de expresión y propaganda gubernamental, en tanto violatoria del artículo 134, párrafos 7 y 8 de la Constitución mexicana. Propaganda con fines de promoción personalizada cuando ésta haya sido contratada con recursos públicos, que tenga un impacto en la equidad de la competencia electoral. Caso Marcelo Ebrard Casaubon, CG353/2012/SUP-RAP-289/2012, los órganos coinciden; Felipe Calderón Hinojosa promoción de su partido en plena campaña electoral CG234/2012, especial sancionador SCG/PE/PRI/CG/078/PEF/155/2012 y SUP-RAP-196/2012 Y ACUMULADOS que evidenció los criterios encontrados en esta materia entre los dos operadores jurídicos, desde luego que coincidimos con el Voto Particular del Magistrado Flavio Galván.

31 Ibidem, pp. 1497-1510. 
Esta revista forma parte del acervo de la Biblioteca Jurídica Virtual del Instituto de Investigaciones Jurídicas de la UNAM

- Libertad de expresión y propaganda electoral. La propaganda política-electoral es válida, siempre y cuando las expresiones denunciadas no supongan una denigración o calumnia a sujeto alguno, es decir, si del análisis de la propaganda no se advierten frases o calificativos que deshonren, difamen o denigren, en su caso, a determinada persona, instituto político, o ente público, debe considerarse que se ubican dentro de la libertad de expresión, la cual en el contexto de un proceso comicial, debe robustecerse y maximizarse. Caso propaganda electoral en el extranjero CG493/2012 declara infundado el Procedimiento especial sancionador, SUP-RAP-386/2012 revoca la resolución del IFE, considerando denigrantes las expresiones del mensaje en contra de Peña Nieto.

- Libertad de expresión y actos anticipados de campaña. La concreción de la afectación, conforme al Consejo General del IFE, de acuerdo a su experiencia en el especial sancionador, habrá de atender a los siguientes elementos: personal, en tanto que son realizados por los partidos políticos, aspirantes, precandidatos y candidatos en el partido político antes del registro de las candidaturas ante la autoridad electoral o antes del inicio formal de las campañas; subjetivo, toda vez que los actos tienen como propósito fundamental presentar una plataforma electoral y promoverse o promover a un ciudadano para obtener un cargo de elección popular; temporal, porque acontecen previamente al registro de las candidaturas ante la autoridad electoral o antes del inicio formal de las campañas. CG331/2012 declara infundados los Procedimientos Especiales Sancionadores incoados en contra de: C. Andrés Manuel López Obrador, candidato a la Presidencia de la República por la coalición "Movimiento Progresista", partidos políticos de la Revolución Democrática, del Trabajo y Movimiento Ciudadano, integrantes de la coalición "Movimiento Progresista”, Movimiento Regeneración Nacional A.C; SUPRAP-269/2012, revoca la resolución.

El cúmulo de procedimientos especiales sancionadores y los criterios que el Consejo General del IFE ha generado en el pasado proceso electoral en relación con la libertad de expresión pueden ser sistematizados, así: 
Esta revista forma parte del acervo de la Biblioteca Jurídica Virtual del Instituto de Investigaciones Jurídicas de la UNAM

- Actos anticipados de campaña.

- Adquisición o contratación de tiempos en radio y/o televisión.

- Difusión de propaganda gubernamental personalizada de servidores públicos.

- Por denigración o calumnia.

- Propaganda contraria a la normativa electoral.

- Incumplimiento a medidas cautelares ordenadas por la Comisión de Quejas y Denuncias.

\section{Instituciones electorales, derecho a la información y medios de comunicación en las campañas presidenciales de 2012}

La Constitución mexicana ordena que las elecciones populares sean "auténticas" y "libres"32 no solamente el día de la jornada electoral sino a lo largo del proceso electoral en su conjunto. Las campañas, por ejemplo, son de capital importancia. Es durante este periodo cuando la ciudadanía puede conocer a los candidatos, los aspirantes están obligados a interactuar con la sociedad y todos tienen la oportunidad para evaluar el pasado y visualizar un nuevo futuro para la nación. Para ello, los ciudadanos deben contar con suficiente información para ejercer su voto el día de la elección, para lo cual las autoridades electorales deben garantizar una plena libertad de expresión y derecho a la información durante las campañas electorales.

\section{Teoría: de la libertad de expresión al derecho a la información}

La naturaleza de la libertad de expresión ha sido definida por el TEPJF que al coincidir con los criterios de la Corte IDH, ha señalado la doble dimensión de esta libertad, una individual y otra social, mismas que se complementan de forma que una no puede subsistir sin la presencia de la otra. Recientemente el Tribunal señaló que:

32 "La renovación de los poderes legislativos y ejecutivo se realizarán mediante elecciones libres, auténticas y periódicas” (artículo 41 de la Constitución mexicana). 
Esta revista forma parte del acervo de la Biblioteca Jurídica Virtual del Instituto de Investigaciones Jurídicas de la UNAM

La libertad como derecho fundamental concebido desde los derechos humanos de primera generación, como una de los tres pilares de los Estados-Nación democráticos, no se agota con el disfrute individual de los sujetos de Derecho, sino que adquiere una dimensión social que influye en la vida en sociedad y se traduce en la necesidad de todo colectivo, de gozar del poder de decisión, sin influencia de algún tipo. ${ }^{33}$

La libertad de expresión no es la excepción, ya que esta doble dimensión que la caracteriza es la que le otorga trascendencia dentro del contexto democrático. En el plano individual, la libertad de expresión comprende el derecho de cada uno de comunicar a otros su propio pensamiento y puntos de vista, lo que trasciende el ámbito personal para insertarse en una dimensión social que implica el derecho de todos a conocer opiniones y noticias. En consecuencia "para el ciudadano común tiene tanta importancia el conocimiento de la opinión ajena, o de la información de que disponen otros, como el derecho a difundir la propia" (énfasis agregado). ${ }^{34}$

La libertad de expresión implica necesaria y simultáneamente el derecho a la información, lo cual ha sido tomado en cuenta por el TEPJF quien no sólo la define como una instancia esencial de autoexpresión, sino además como condición indispensable para ejercer otros derechos y como elemento determinante para la calidad de vida democrática de un país. ${ }^{35}$

La libertad de expresión no tiene que ver únicamente con la autonomía de los individuos, sino que por medio de ellas los receptores de la información pueden tener a su alcance la más diversa variedad de opiniones y puntos de vista en torno a un tema determinado. ${ }^{36}$ Asimismo, el contenido de la libertad de expresión se compone de tres elementos: 1) derecho a atraerse información; 2) derecho a informar, y 3) derecho a ser informado. ${ }^{37}$

33 Cómputo Final, Calificación Jurisdiccional de la Elección, Declaración de Validez y de Presidente Electo de los Estados Unidos Mexicanos, p. 98.

34 Juicio de Inconformidad. SUP-JIN 359/2012, Sala Superior, TEPJF, p. 107.

35 SUP-JIN 359/2012, pp.111-112.

36 Saba, Roberto, "El derecho de la persona a acceder a la información en poder del gobierno", Derecho Comparado de la Información, núm. 3, enero-junio de 2004, p.153.

37 Villanueva, Ernesto, "Derecho de Acceso a la Información Pública”, en Latinoamérica: Estudio Introductorio y Compilación, México, UNAM, Instituto de Investigaciones Jurídicas, 2003, p. XVII. 
Esta revista forma parte del acervo de la Biblioteca Jurídica Virtual del Instituto de Investigaciones Jurídicas de la UNAM

Definida la naturaleza y contenidos de la libertad de expresión, habría que considerar reconceptualizar la libertad de expresión para entenderla no sólo como una libertad negativa, sino como una libertad positiva, en términos de Isaiah Berlin. ${ }^{38}$ Una libertad negativa se entiende como aquella que nos permite escapar o "liberarnos de" controles impuestos de manera externa. Pero una libertad positiva va más allá, puesto que nos permite no sólo escapar, sino avanzar hacia nuestra realización plena como seres humanos, es decir, nos permite "liberarnos hacia" el cumplimiento de una meta particular. Consideramos por ello que, una vez que conceptualizamos las libertades de expresión y opinión como derechos hacia la realización de seres humanos plenamente informados y no sólo como garantías para liberarnos de la censura, entramos al terreno del derecho a la información entendido en su forma más amplia.

\section{Práctica: libertad empresarial sin información ciudadana}

Discursivamente tanto el IFE como el TEPJF han defendido una sofisticada teoría de la libertad de expresión y el derecho a la información. Sin embargo, durante el desarrollo del proceso electoral de 2012, pudo constatarse la aplicación de una visión minimalista y parcial del concepto por parte de las autoridades, lo cual se evidenció en los siguientes ejemplos.

\section{A. Sugerencias de lineamientos}

El artículo 49.7 del Cofipe establece que la autoridad electoral deberá establecer sugerencias de lineamientos respecto de la cobertura que los noticieros hagan de las actividades de campañas y precampañas. El acuerdo CG 291/2011 instrumentó estas sugerencias de lineamientos, sin embargo, llama la atención cómo este documento refleja una visión diferente del concepto de libertad de expresión descrito arriba.

En principio, el IFE considera que el objetivo de los lineamientos debe ser el de "conciliar" o "equilibrar" el derecho a la información de los ciudadanos con la libertad de expresión de los medios de

38 Berlin, Isaiah, “Two Concepts of Liberty”, en id., Four Essays on Liberty, London, Oxford University Press, 1969. Ver nueva edición en Berlin, 2002. 
comunicación, ${ }^{39}$ lo cual se contrapone a la concepción dual de estos derechos, por lo que se coloca en el mismo nivel de importancia el derecho de una persona de expresarse y de la sociedad a recibir dicha información. El IFE presenta a la libertad de expresión como un derecho exclusivo de los medios, restando importancia al ejercicio que de la misma hagan los ciudadanos. Queda fuera, por ejemplo, cualquier exigencia con respecto a la inclusión de una pluralidad de voces ciudadanas dentro de los medios de comunicación.

\section{B. Monitoreo de radio y televisión}

En cumplimiento del artículo 76.8 del Cofipe, el IFE realizó un monitoreo de noticieros en radio y televisión en colaboración con la Facultad de Ciencias Políticas y Sociales de la UNAM, con el objeto de vigilar el nivel de cumplimiento de las "sugerencias de lineamientos". Sin embargo, aun cuando la UNAM fue la institución encargada de realizar el monitoreo, éste se hizo atendiendo a la metodología impuesta por el IFE y tomando en cuenta las variables que la autoridad consideró adecuadas.

El enfoque principal del monitoreo se dio cuantitativamente sobre las menciones y tiempo total dedicado a cada candidato y partido. En el aspecto cualitativo únicamente se tomó en cuenta la vigilancia de los recursos técnicos utilizados, la jerarquización temporal de las notas dentro del noticiero y la "adjetivización" de las notas, por la cual se midieron las valoraciones positivas o negativas para cada candidato. Cuantitativamente, se dejaron de lado aspectos como el tipo y calidad de la cobertura, el análisis de la construcción visual y conceptual que los medios hacen sobre las notas y la exclusión del estudio de programas de debate y análisis.

El monitoreo, lejos de realizar un estudio que evidenciara algún tipo de sesgo mediático, se limitó a una simple actividad de contabilización de menciones y tiempos sin realizar un ejercicio intelectual más profundo. No obstante lo anterior, pueden extraerse datos importantes para demostrar una ventaja mediática significativa a favor del candidato del PRI Enrique Peña Nieto, quien del total del tiempo monitoreado recibió un $30.64 \%$ de cobertura, Josefina Vázquez Mota

39 Acuerdo CG 291/2011, Consejo General, IFE. pp. 6 y s. 
Esta revista forma parte del acervo de la Biblioteca Jurídica Virtual del Instituto de Investigaciones Jurídicas de la UNAM

26.52\% y Andrés Manuel López Obrador un 26.36\%. ${ }^{40}$ De igual forma, fue el único candidato en recibir más valoraciones positivas que negativas en televisión, situación contraria a la de sus adversarios, de quienes se habló negativamente en distintas piezas informativas, más que de forma positiva. ${ }^{41}$ En cuanto al tiempo medido por género periodístico, por ejemplo, la entrevista, se obtuvo que Peña Nieto pudo hablar en vivo 175 horas, mientras que López Obrador sólo pudo hacerlo en un total de 79 horas, ${ }^{42}$ lo que evidencia un porcentaje mucho mayor de cobertura para el candidato priista en un formato mucho más accesible y convincente para el votante común.

\section{Debates electorales}

Dos momentos clave marcaron la actuación de las autoridades en este tema. El primero, cuando Andrés Manuel López Obrador solicitó al IFE la realización de 12 debates entre candidatos presidenciales; el segundo, cuando esta autoridad tuvo que resolver la pertinencia de solicitar la transmisión en cadena nacional del segundo debate.

Respecto del primer caso, el candidato apeló a una interpretación que maximizara el derecho a la información de los ciudadanos, lo cual se debería hacer observando lo dispuesto en el artículo primero constitucional, los tratados internacionales y con base en una aplicación del principio pro homine. La autoridad consideró, sin embargo, que el artículo 70 del Cofipe no debía ser interpretado extensivamente, pues su contenido es impositivo, es decir, establece una obligación a cargo de la autoridad que por ser tal, debe observarse estrictamente so pena de contravenir los principios de legalidad y seguridad jurídicas, lo que implicaría crear nuevas obligaciones no previstas en la ley a cargo de los permisionarios públicos obligados a transmitir los debates. ${ }^{43}$

40 Monitoreo de Espacios Noticiosos en Radio y Televisión. Campaña Electoral para presidente de la República 2011-2012, UNAM, Facultad de Ciencias Políticas y Sociales, (en adelante "Monitoreo de Espacios"), p. 9. Disponible en: http://www.monitoreoifeunam. $m x /$ reportes/BaseCreacionGraficasEstaticas/presidente/data/periodo/2012-03-30_ al_2012-06-27/documentos/Reporte_Presidente_del_2012-03-30_al_2012-06-27.pdf (Consultado el 29 de octubre de 2012).

41 Ibidem, p. 18.

42 Ibidem, p. 14.

43 Acuerdo CG-118/2012, Consejo General del IFE. 
Esta revista forma parte del acervo de la Biblioteca Jurídica Virtual del Instituto de Investigaciones Jurídicas de la UNAM

Consideramos que el Cofipe en su artículo 70, de ninguna manera prohíbe al IFE organizar más debates entre los presidenciables. Recordemos que en 2006 el IFE participó activamente en la organización de dos debates, ninguno requerido por la ley. En 2012, sin embargo, cambió de criterio para condicionar su intervención en debates adicionales a los ordenados por el artículo 70 al acuerdo unánime entre los candidatos, lo cual permitía que cualquiera a quien conviniera reducir al mínimo los momentos de intercambio libre de ideas con sus contrincantes pudiera vetar la realización de ejercicios adicionales.

El caso llegó al TEPJF, quien ratificó la postura del IFE y sostuvo que esta autoridad no está facultada para organizar debates distintos a los dos ordenados por el Cofipe, ${ }^{44}$ lo que no significa una restricción a los medios de comunicación para organizar libremente debates, siempre y cuando no exista de por medio la compra o adquisición de "espacios" por parte de algún candidato o partido. Una interpretación interesante, sin embargo, podría justificar lo que terminó por ocurrir en la realidad, que los medios no convocaran, salvo algunas excepciones, a nuevos debates que generaran un contexto de exigencia hacia los candidatos.

En el segundo caso, como resultado de la abierta provocación de las televisoras para darle menor difusión al debate presidencial, se solicita al IFE que realice un esfuerzo para instar a la Secretaría de Gobernación (Segob) su difusión en cadena nacional, a lo cual la autoridad se negó, abdicando su responsabilidad de garantizar el derecho a la información de los mexicanos. Los consejeros electorales subrayaron que no se encuentra dentro de las facultades del IFE el obligar a los concesionarios a transmitir el debate, sin embargo, lo que estaba bajo discusión no era que la autoridad impusiera directamente la cadena nacional, sino que realizara las gestiones necesarias para que las autoridades correspondientes intervinieran para garantizar el derecho a la información de los ciudadanos.

El TEPJF confirmó nuevamente la postura del IFE, con la anotación de que realizara las gestiones a su alcance para tener certeza de que el debate tuviera la mayor difusión posible. ${ }^{45}$ Es claro que la propuesta no consistía en obligar a los ciudadanos a ver el debate. Al contrario, lo que se buscó era garantizar que todos tuvieran la posibilidad de

44 SUP-RAP-94/2012

45 SUP-RAP-198/2012 
Esta revista forma parte del acervo de la Biblioteca Jurídica Virtual del Instituto de Investigaciones Jurídicas de la UNAM

atestiguar el evento político, algo que solamente se podría lograr con su transmisión por los canales de mayor cobertura. Si una persona no quisiera atender la cadena nacional, siempre existe la opción de apagar el televisor, pero la cuestión radicaba en demostrar la fortaleza de la autoridad ante el abierto acto de sabotaje de parte de las principales televisoras.

\section{La promoción del voto razonado mediante la organización de debates electorales}

México es hoy en día un Estado democrático de derecho que busca cumplir con los objetivos políticos que caracterizan el funcionamiento de esta conformación política. En este contexto, la libertad de expresión como eje fundamental del ejercicio democrático ha transitado de un liberalismo individualista a una noción de equidad colectiva donde se procura la igualdad de condiciones para que todos los miembros de la sociedad se expresen por igual.

En el ejercicio de libertad de expresión en un Estado democrático, los medios de comunicación se erigen como poderosos actores de influencia política, frente a esta situación el Estado ha intentado regular la actuación de los medios de comunicación en el ámbito de la comunicación política, en busca de la construcción de un escenario equitativo. En el modelo democrático estatal esta regulación tiene como objetivo aumentar y mejorar el debate público.

La racionalidad de la regulación de los medios de comunicación es buscar la equidad tanto de emisores de expresiones y opiniones, como de los receptores de la información. Entre más participación existe de unos y otros, el debate público es más rico y amplio, de manera que la sociedad produce información constante hasta poder influir el sentir y actuar de legisladores y políticos.

El Estado es promotor de la libertad de expresión, no sólo cuida la expresión de sus ciudadanos, sino también se encarga de la comunicación de los actores políticos, la llamada comunicación política. En cuanto a las expresiones e ideas del Estado mismo, su actuar ha transitado a un esquema de transparencia y acceso a la información. La libertad de expresión en el campo electoral es relevante en un Estado 
Esta revista forma parte del acervo de la Biblioteca Jurídica Virtual del Instituto de Investigaciones Jurídicas de la UNAM

democrático por tratarse del ámbito limítrofe entre el actuar público y el actuar ciudadano.

Los instrumentos o espacios que contribuyan a dar más y mejor información por parte de la esfera estatal son relevantes porque incrementan la participación política y de esa manera fortalecen la vida democrática. Sin embargo, las obligaciones del Estado democrático de proveer información del actuar público a la ciudadanía y mejorar el debate público, generan problemas de los cuales destacan la falta de autonomía del Estado, el nivel de formación de la ciudadanía y la inequidad informativa.

La comunicación política en la competencia electoral se convierte en un poderoso instrumento para mejorar directamente el debate público, buscando la autonomía de los planteamientos o por lo menos la existencia de una pluralidad de posiciones, así como la existencia de equidad, para ello el Estado intenta regular la propia comunicación electoral.

Es así como los debates políticos surgen bajo la premisa de combinar las tres grandes necesidades de la comunicación política democrática: la libertad de expresión de actores políticos; el derecho de los ciudadanos a ser informados y un mismo espacio que optimice las posibilidades de recepción del electorado de un debate público de calidad.

Los debates políticos surgieron como una necesidad de vinculación entre aspirantes a puestos de elección democrática y el electorado, primero sin regulación, como manifestación de la libertad de individuos, y después como un ejercicio democrático equitativo. Con este nuevo enfoque, la equidad y la regulación se vuelven cuestiones centrales en los debates políticos.

La equidad implica la posibilidad de que todos los candidatos a una elección participen en los debates políticos. Cuando la organización de estos debates es predominantemente pública, la equidad es total a través de regulación, en cambio, cuando la organización es predominantemente privada, la equidad es relativa. No obstante, entre los dos tipos de organizaciones, existen matices en la presentación de debates.

La segunda cuestión sobre los debates políticos es sobre el tipo de regulación que enmarcará a estos ejercicios, es decir, si la regulación será en materia de radio y televisión o en materia electoral. Cierto es que no siempre regula un órgano estatal, se observan en la mayoría de 
Esta revista forma parte del acervo de la Biblioteca Jurídica Virtual del Instituto de Investigaciones Jurídicas de la UNAM

las democracias del mundo reglas que de común acuerdo, a partir de negociaciones, establecen los propios participantes.

La regulación de los debates electorales afecta profundamente el alcance e impacto de los mismos. El nivel de regulación está determinado por quién determina las mismas, la autoridad, los partidos políticos, los medios de comunicación o la ciudadanía; normalmente la regulación es por parte de varios o todos estos actores. Se observa que cuando la ciudadanía regula los debates, no se trata de la ciudadanía abierta, sino de organizaciones sociales que tienden a tener sus propias agendas e intereses.

En las democracias actuales podemos encontrar distintos matices en la organización y regulación de los debates. En Estados Unidos de América, por ejemplo, son las organizaciones no gubernamentales quienes organizan los debates y, al igual que en España, sistemáticamente se han excluido a los candidatos de los partidos minoritarios, mientras que en Chile en el penúltimo debate de 2005 se incluyeron a todos los candidatos. En Francia la organización de los debates políticos queda en manos de las cadenas de televisión, en cambio, Colombia sólo organiza debates políticos en caso de segunda vuelta electoral.

En México, la tradición de los debates políticos inició sin existir mandato de ley. Fue hasta la reforma electoral de $1996^{46}$ cuando se estableció que el IFE a petición de los partidos, organizaría y apoyaría la difusión de los debates.

Los debates del año 2000 fueron un ejercicio privado, donde el primer debate de ese año fue incluyente de todos los partidos y en el segundo sólo participaron las principales fuerzas políticas.

En 2006 el IFE desempeñó un rol de mediador y facilitador, pues al no tener una facultad u obligación expresa en la ley, quedaba a los propios actores el decidir la logística y detalles de la organización.

Fue en la reforma electoral de 2007 cuando se estableció la obligación del IFE de organizar dos debates, sin embargo, faltó establecer obligación alguna a los partidos políticos y a los concesionarios respecto a su participación en los mismos. En los debates de 2012 se lograron consensos entre candidatos y partidos procurando flexibilidad.

El resultado de los debates políticos puede mejorar si se pone en primer lugar el interés de la ciudadanía con formatos más dinámicos.

46 El Decreto que reforma el Cofipe fue publicado el viernes 22 de noviembre de 1996 en el Diario Oficial de la Federación, entrando en vigor el mismo día. 
Esta revista forma parte del acervo de la Biblioteca Jurídica Virtual del Instituto de Investigaciones Jurídicas de la UNAM

La creciente exigencia de participación de los ciudadanos da un nuevo matiz a la comunicación política y a la misma participación ciudadana en la democracia mexicana.

La autoridad electoral en principio, así como la legislativa, en caso de que se efectúe una reforma electoral integral, deberá considerar si este modelo es suficiente, o si bien, para cumplir con las demandas de participación tendrá que regular aspectos técnicos de organización.

Finalmente, el papel en los debates electorales de los nuevos medios de participación y comunicación, las llamadas redes sociales, y el enfoque de la ciudadanía como objetivo y racionalidad de estos ejercicios para transmitir propuestas e ideas y no meras exposiciones unilaterales, son dos elementos que deben considerarse sobre el futuro del modelo regulador de debates políticos.

\section{La libertad de expresión y el derecho de réplica}

El apartado desarrolla, con una perspectiva jurídica-doctrinaria, el derecho de réplica como un derecho humano que deriva a su vez del derecho a la libertad de expresión surgido en el siglo XVIII en el marco del Estado constitucional. Así, partimos del hecho que los derechos de réplica y de expresión no podrían entenderse el uno sin el otro: una sociedad que no está bien informada no es plenamente libre y, por ello, las Constituciones reconocen y garantizan estos derechos.

A ese respecto, el derecho a la libertad de expresión se encuentra en el artículo 6o. de la Constitución mexicana vigente de 1917 desde su texto original. Sin embargo, observamos en cuanto al derecho de réplica que, después de 218 años de la publicación de la Declaración Francesa de los Derechos del Hombre y del Ciudadano de 1789, se plasmó en ese mismo artículo con la reforma del 13 de noviembre de 2007. Asimismo, la regulación para ejercer dicho derecho, de acuerdo con los artículos transitorios tercero y sexto de la citada reforma, se dejó a una ley federal específica que debía publicarse en un plazo máximo de 30 días naturales contados a partir del inicio de la vigencia de la reforma constitucional, esto es, el plazo se venció el 13 de diciembre de 2007.

Con relación a lo anterior, el artículo décimo transitorio del Cofipe, publicado el 14 de enero de 2008, señala una fecha distinta a la refor- 
Esta revista forma parte del acervo de la Biblioteca Jurídica Virtual del Instituto de Investigaciones Jurídicas de la UNAM

ma constitucional del artículo 6o., al establecer que a más tardar el 30 de abril de 2008 el Congreso de la Unión debía expedir la ley reglamentaria del derecho de réplica.

La reforma constitucional del 13 de noviembre de 2007, en su artículo sexto transitorio, dispuso que las legislaturas de los estados y la Asamblea Legislativa del Distrito Federal estarían obligadas a adecuar su legislación aplicable a más tardar en un año a partir de la entrada en vigor de la reforma, esto es el 13 de noviembre de 2008 y que, en caso de no ser así, se observaría lo dispuesto en el artículo 105, fracción II, párrafo cuarto de la Constitución mexicana, el cual se refiere a que las leyes federales y locales deberán publicarse por lo menos 90 días antes de que inicie el proceso electoral en que vayan a aplicarse, y con la prohibición expresa que durante dicho proceso electoral no habrán modificaciones.

En cuanto al ámbito local, existen normas jurídicas que hacen referencia a la réplica, por ejemplo, en los estados de Chiapas, Chihuahua, Colima, Guanajuato, Hidalgo, Michoacán, Puebla, Quintana Roo, Sinaloa, Sonora, Tlaxcala, Veracruz, Yucatán, Tamaulipas, y el Distrito Federal. Mientras que en el contexto federal existe una importante dispersión de normas jurídicas sobre la réplica. Se puede afirmar que la Ley sobre Delitos de Imprenta puede ser reglamentaria del actual artículo 6o. constitucional, sin embargo, resulta necesario analizar a profundidad cuáles han sido los criterios de la SCJN en esta materia. Asimismo, se encuentra el Reglamento de la Ley Federal de Radio y Televisión en materia de concesiones, permisos y contenido de las transmisiones de radio y televisión, el cual señala que en la democracia la libertad de expresión debe ejercerse con respeto absoluto a los derechos de réplica y de privacía de los(as) ciudadanos(as) frente a los medios de comunicación, de manera que tanto ciudadanos(as) como comunicadores(as) puedan defender el derecho para preservar su dignidad, y que la radio y televisión promoverán el derecho de réplica para que la persona lo ejercite y, en caso de que la estación de radiodifusión estime que la aclaración solicitada es improcedente, la persona tendrá a salvo sus derechos para recurrir a las vías jurisdiccionales correspondientes.

Por lo anterior, consideramos que la ausencia de una regulación legal específica del derecho de réplica facilita que algunas personas realicen prácticas absolutistas, aun en un Estado constitucional que lo reconoce, sin embargo, una de las característica del Estado en comen- 
Esta revista forma parte del acervo de la Biblioteca Jurídica Virtual del Instituto de Investigaciones Jurídicas de la UNAM

to, consiste en que este derecho goce de una regulación detallada en una ley publicada.

En ese orden de ideas, y también considerando el contenido de los artículos 1, 14, 16, 71, 72 y 89 de la Constitución mexicana, la promulgación de leyes que garanticen el derecho de réplica, rectificación o respuesta tienen como resultado la protección a la vida privada de todas las personas sin hacer un uso desproporcional de los poderes coactivos del Estado. Así, y considerando que las declaraciones en el ámbito político se realizan frecuentemente mediante juicios de valor y no mediante una afirmación exhaustivamente basada en hechos, no debería existir ningún tipo de responsabilidad pues se trata de una apreciación subjetiva y ésta no puede ser sometida a prueba para su veracidad o falsedad.

En este contexto, una ley del derecho de réplica tendría que aplicarse por extensión también en el ámbito del derecho electoral. Sin embargo, esta ley aunque era obligación tenerla desde 2008, no existe. En este contexto, en octubre de 2011 inició el proceso electoral para las elecciones federales de 2012 y se presentaron diversos casos relativos al ejercicio del derecho de réplica, por ejemplo, los asuntos de los cuales conoció el IFE sobre esta materia los tramitó de acuerdo a las reglas del procedimiento especial sancionador.

Por su parte, el TEPJF estimó que se debe aplicar, como criterio orientador, lo señalado en el artículo 27 de la Ley sobre Delitos de Imprenta en tanto se expide la ley de la materia, asimismo, consideró que la omisión legislativa no impide que se ejerza un derecho humano, y menciona que la ausencia de una ley sobre el derecho de réplica, vinculado con la materia electoral, no es óbice para que el IFE, como órgano del Estado mexicano, en ejercicio de sus atribuciones y en cumplimiento a las disposiciones normativas de la Constitución mexicana y de los tratados internacionales suscritos y aprobados por México, adopte las medidas instrumentales pertinentes cuando se le hace valer el respeto al derecho de réplica.

En ese tenor, la SCJN desde 1997 ha ampliado sus facultades a través de su jurisprudencia constitucional para reconocer, cuando se presenten casos de omisión legislativa, la vía del amparo indirecto, la procedencia de la acción de inconstitucionalidad, así como la posibilidad de que se presente una controversia constitucional. Para ello, la SCJN debe formular una especie de exhorto a los(as) legisladores(as) fede- 
Esta revista forma parte del acervo de la Biblioteca Jurídica Virtual del Instituto de Investigaciones Jurídicas de la UNAM

rales para que de inmediato cumplan con todo el proceso legislativo y se publique una determinada ley. ${ }^{47}$

Recientemente, una jurisprudencia constitucional de enero de 2010 señala que la única vía para plantear la no conformidad de las leyes electorales con la Constitución mexicana es la acción de inconstitucionalidad — de la que conoce y resuelve sólo la SCJN-, y que la jurisprudencia de su pleno, cuando se refiere a la interpretación directa de un precepto de la Constitución mexicana, es obligatoria para el TEPJF. Sin embargo, el TEPJF en su sentencia del 30 de agosto de 2012 y respecto del juicio de inconformidad, expediente: SUP-JIN-359/2012, para el caso del derecho de réplica no consideró resolución alguna de la SCJN.

Por otra parte, la Comisión Interamericana de Derechos Humanos $(\mathrm{CIDH})$ y la Corte IDH han abierto el debate sobre el tema del derecho de réplica y han emitido consideraciones en materia del ejercicio de este derecho y, particularmente, en el ámbito electoral.

En materia electoral, las elecciones a cargos de representación popular constituyen uno de los momentos fundamentales de la participación política de las personas y la vida democrática, es por ello que los procesos electorales están íntimamente vinculados a la libertad de expresión e información, así, para que los(as) ciudadanos(as) puedan llevar adelante sus decisiones en el momento de votar, es indispensable que cuenten con la mayor cantidad de información, lo cual es posible por medio de la realización de debates políticos democráticos durante un proceso electoral entre los(as) candidatos(as) y sus partidos políticos a través de los medios de comunicación, de los propios candidatos(as) y de cualquier persona que desee expresar su opinión o brindar información, ya que todos(as) deben estar en posibilidad de preguntar, cuestionar e indagar sobre la capacidad, pensamiento, ideología, trayectoria política y/o académica, sencillez, imagen, temperamento, modo y lenguaje verbal, vínculos políticos y personales, liderazgo, principios y valores, nivel de escolaridad, e idoneidad de los(as) candidatos(as), así como disentir y confrontar sus propuestas,

47 Para ampliar el tema, se sugiere consultar Astudillo, César, "La inconstitucionalidad por omisión legislativa en México", en Carbonell, Miguel (coord.), En busca de las normas ausentes. Ensayos sobre inconstitucionalidad por omisión, México, 2a. ed., UNAM, Instituto de Investigaciones Jurídicas, 2007, pp. 315 y ss. 
Esta revista forma parte del acervo de la Biblioteca Jurídica Virtual del Instituto de Investigaciones Jurídicas de la UNAM

ideas y opiniones. Para ello es crucial que los hechos, las ideas y las opiniones circulen libremente. ${ }^{48}$

No obstante, cuando los partidos políticos o candidatos(as) hayan o presuman que han sido difamados(as) de manera ilegítima o hayan sufrido algún perjuicio ilegítimo como resultado de declaraciones formuladas en los medios de comunicación durante un proceso electoral, debe reconocerse y garantizarse el derecho a que rectifiquen inmediatamente las referidas declaraciones o a que reclamen una reparación ante los tribunales de justicia. Cuando se opte por esta última vía se debe asegurar la garantía de todos los derechos en juego y determinar el carácter inexacto o agravante de la información, dado que ya hay un conflicto o diferencia que resulta del intento de hacer valer, en un caso o situación concreta, el derecho de rectificación o respuesta.

Al regular la aplicación del derecho de réplica, rectificación o respuesta, se debe respetar el derecho de libertad de expresión, pero este último no puede interpretarse de manera tan amplia que haga nugatorio aquél derecho.

El derecho de réplica es una vía externa, es decir, no existe la necesidad de ejercer los derechos a la procuración y administración de justicia para que una persona pueda defender su dignidad, honor, vida privada o imagen, por la difusión de información inexacta, equivocada o injuriosa. Asimismo, es un derecho que se encuentra presente entre los emisores y receptores de la información y que fomenta la veracidad en la información que transmiten los medios de comunicación a la opinión pública, de este modo, el ejercicio del derecho de réplica debe limitarse sólo a aclarar o responder los datos incompletos o falsos.

Con el derecho de rectificación o respuesta no se busca tener un mecanismo por el cual se puedan determinar responsabilidades ulteriores, ya sean de carácter civil o penal, para proteger otros derechos, sino un medio menos restrictivo para dar preferencia y no inhibir el debate amplio y plural sobre asuntos de interés público.

A ese respecto, y de manera particular, en el ámbito del derecho electoral existen diversas iniciativas de ley en la materia que ya

48 Cfr. Informe anual de la relatoría para la libertad de expresión 2005. Capitulo VI. Libertad de expresión y procesos electorales: el caso de las encuestas y los sondeos de boca de urna, Disponible en: http://www.oas.org/es/cidh/expresion/showarticle.asp ? $\operatorname{artID}=662 \mho l I D=2$, consultada el 7 de septiembre de 2012, párrs. 1 a 4, 13 y 46, y Corte IDH, caso Ricardo Canese vs. Paraguay, Sentencia de 31 de agosto de 2004. 
Esta revista forma parte del acervo de la Biblioteca Jurídica Virtual del Instituto de Investigaciones Jurídicas de la UNAM

han presentado los(as) legisladores(as) del Congreso, por lo que las reflexiones sobre este tema se sugiere sean consideradas en las diversas iniciativas de ley sobre el derecho de réplica que ya se presentaron en las Cámaras del Congreso, pero que a grandes rasgos para nosotros dichas iniciativas no contemplan diversos puntos fundamentales abordados en este trabajo y que, por lo mismo, podrán existir datos coincidentes respecto a qué significa el derecho de réplica establecido en el artículo 6o. de la Constitución mexicana, pero los procedimientos para ejercerlo y garantizarlo son diversos y, es donde creemos, que las instituciones del Estado tienen un papel importante que hacer para garantizarlo y no es un tema que, ante la presencia de la presunta violación del derecho de réplica, los medios de comunicación sean, por sí solos y sin un procedimiento, los que resuelvan si procede o no el ejercicio de este derecho y no haya una institución del Estado que intervenga, cuando menos, en su papel de mediador o en materia de administración de justicia.

A ese respecto, dentro del "Pacto por México", suscrito por el presidente de México y de los partidos políticos, Partido de la Revolución Democrática (PRD), Partido Acción Nacional (PAN) y Partido Revolucionario Institucional, en el punto 5. Acuerdos para la Gobernabilidad Democrática, y 5.8. Medios de Comunicación, se menciona que se dará cumplimiento a la reforma constitucional del 13 de noviembre de 2007, para garantizar el derecho de réplica.

\section{Libertad de expresión en Internet y redes sociales en la democracia en México: aproximación jurídica en materia electoral}

Actualmente, Internet y las redes sociales juegan un papel muy importante en el ámbito de la libertad de expresión, los derechos humanos y la democracia, con una especial incidencia en este último rubro en la materia electoral, en lo que concierne a temas como reflexión, opinión, crítica y fiscalización, entre otros.

Ahora bien, la conjugación de todos estos aspectos dan pauta a una serie de planteamientos muy significativos de inexorable punto de inflexión, concernientes a la actuación de actores protagónicos como el Estado; defensoría de derechos humanos; autoridades electorales 
Esta revista forma parte del acervo de la Biblioteca Jurídica Virtual del Instituto de Investigaciones Jurídicas de la UNAM

tanto sustantivas como adjetivas, así como en materia de transparencia de información y protección de datos personales; partidos políticos, coordinadores de campañas, equipos de apoyo, afiliados, simpatizantes y especialmente a las candidatas y candidatos a cargos de elección popular; medios de comunicación nacionales e internacionales; proveedores de servicio de Internet (ISP); empresas nacionales y extranjeras, así como particulares de otros países ajenos a una elección nacional; observadores electorales nacionales e internacionales, y por supuesto los ciudadanos, entre otros.

En el caso de México los alcances del artículo 41 constitucional relativos a la libertad de expresión para favorecer una equitativa contienda electoral, están acotados por cuanto concierne al uso de Internet y las redes sociales, por lo que es conveniente reflexionar si se recurre a una interpretación o en su caso, a una explicitación de dicho texto a través de una reforma.

Mucho se ha debatido sobre la conveniencia de contemplar a Internet como un derecho fundamental a partir de nuestra Carta Magna (recientemente la ONU lo consideró como un derecho humano), y por otro lado, de regular legalmente a Internet y las redes sociales, sin embargo, respecto a este último punto, actualmente se ha optado por recurrir a la figura de la autorregulación ante los eventuales riesgos de trastocar derechos básicos como la libertad de expresión y la privacidad y en su caso entorpecer un adecuado desarrollo democrático de la sociedad, actualmente caracterizada por estar cada vez más informada, ser más crítica y más ávida de transparencia y rendición de cuentas por parte del Estado.

Sin duda alguna Internet y las redes sociales han cambiado la forma en la que vivimos, la forma en la que concebimos el mundo, modificando nuestros pensamientos y sentimientos. Actualmente Internet y la llamada Web 2.0 (blogs, wikis y redes sociales) se han convertido en un instrumento de comunicación vertical y horizontal altamente significativo en el ámbito de la democracia, al grado de dar pauta a nuevos conceptos como el ágora digital y los ciberciudadanos o ciudadanos 2.0, por mencionar sólo algunos.

En este documento se hace un análisis de la llamada Declaración conjunta sobre libertad de expresión en Internet, adoptada por la Organización de Estados Americanos (OEA) el 1o. de junio de 2011 que establece principios generales relativos a Internet y las redes sociales a la luz de la libertad de expresión con una concepción renovada del 
Esta revista forma parte del acervo de la Biblioteca Jurídica Virtual del Instituto de Investigaciones Jurídicas de la UNAM

papel de los Estados, empresas y sociedad en general respecto al ejercicio de la libertad de expresión en la era digital.

De igual manera se presenta un panorama del uso de Internet y redes sociales en materia político-electoral en México y en el extranjero y su incidencia cada vez más creciente en dicho ámbito. Este rubro viene acompañado de una serie de reflexiones sobre la eventual necesidad de incorporar consignas específicas en las legislaciones electorales sustantivas y adjetivas que por un lado estimulen el buen uso de estas importantes herramientas tecnológicas y por el otro sancionen el uso inadecuado de las mismas.

En suma, una temática muy interesante y actual de obligada comprensión y reflexión que indubitablemente seguirá dando mucho de qué hablar en los años venideros, dentro de la comunidad social en general y jurídica en particular.

\section{Fuentes consultadas}

AcKerman, John M., Elecciones 2012: en busca de equidad y legalidad, UNAM, Instituto de Investigaciones Jurídicas-Senado de la República, México, 2011.

- - - Nuevos escenarios del derecho electoral: los retos de la reforma de 2007-2008, UNAM, Instituto de Investigaciones Jurídicas, 2009. Arendt, Hanna, La condición humana, Barcelona, Paidós, 1993.

Astudillo, César, "La libertad de expresión en el contexto del modelo de comunicación político-electoral", Revista Mexicana de Derecho Electoral, núm. 3, México, UNAM, Instituto de Investigaciones Jurídicas, enero-junio 2013.

- - - "El nuevo sistema de comunicación política en la reforma electoral de 2007", en Córdova Vianello, Lorenzo y Salazar Ugarte, Pedro (coords.), Estudios sobre la reforma electoral 2007. Hacia un nuevo modelo, México, TEPJF, 2009, t. I.

- _ , "La inconstitucionalidad por omisión legislativa en México", en Carbonell, Miguel (coord.), En busca de las normas ausentes. Ensayos sobre inconstitucionalidad por omisión, México, 2a. ed., UNAM, Instituto de Investigaciones Jurídicas, 2007.

Berelson, Bernard y Janowitz, M., Public Opinion and Communication, Glencoe, Ill, 2a. ed., Nueva York, The Free Press, 1966. 
Esta revista forma parte del acervo de la Biblioteca Jurídica Virtual del Instituto de Investigaciones Jurídicas de la UNAM

Berlin, Isaiah, "Two Concepts of Liberty”, en Idem, Four Essays on Liberty, London, Oxford University Press, 1969.

Воввіо, Norberto, Igualdad y libertad, trad. de Pedro Aragón Rincón, Barcelona, Paidós, 1993.

_-_, El tiempo de los derechos, Madrid, Sistema, 1991.

_-_, Fundamento y futuro de la democracia, Valparaiso, EDEVAL, 1990.

_- - Liberalismo y democracia, trad. de José Fernández Santillán, México, Fondo de Cultura Económica, 1989.

_-_, Estado, gobierno y sociedad, México, FCE, 1989.

Calvert, Clay, "When First Amendment principles collide: Negative political advertising \& the demobilization of democratic self-governance", Loy Law Review, num. 30, L.A., Loyola Marymount University and Loyola Law School, 1997.

Carbonell, Miguel, "La libertad de expresión en materia electoral", Temas selectos de Derecho Electoral, núm. 3, México, TEPJF, 2010.

Chaffe, Steven (comp.), Political comunication, Beverly Hills, Sage, 1975.

Concha Cantú, Hugo Alejandro, "Derechos políticos y construcción de ciudadanía”, en Ackerman, John M., (coord.), Elecciones 2012, en busca de equidad y legalidad, UNAM, Instituto de Investigaciones Jurídicas, 2011.

Córdova Vianello, Lorenzo, "Las razones y el sentido de la reforma”, en Idem y Salazar Ugarte, Pedro, Estudios sobre la reforma electoral 2007. Hacia un nuevo modelo, México, TEPJF, 2008.

Corte IDH, caso Ricardo Canese vs. Paraguay, Sentencia de 31 de agosto de 2004.

Cruz Parcero, Juan Antonio, "La libertad de expresión y los límites impuestos por la reforma del artículo 41 constitucional. Aspectos problemáticos", en Córdova VIANELlo, Lorenzo y SALAzAR UGARTE, Pedro (coords.), Estudios sobre la reforma electoral 2007. Hacia un nuevo modelo, México, TEPJF, 2009.

DADER, José Luis, "La ciberdemocracia posible. Reflexión prospectiva a partir de la experiencia en España", CIC Cuadernos de Información y Comunicación, núm. 6, Madrid, UCM, 2001.

Ferrajoli, Luigi, "Jueces y política", Derechos y libertades, Revista del Instituto Bartolomé de las Casas, Año IV, núm. 7, enero, 1999.

Fiss, Owen, The Irony of Free Speech, Cambridge, Massachusetts, Harvard University Press, 1996. 
Esta revista forma parte del acervo de la Biblioteca Jurídica Virtual del Instituto de Investigaciones Jurídicas de la UNAM

Flores, Imer B., "Equidad social”, en FiX-Zamudio, Héctor y ValaDÉs, Diego (eds.), Instituciones sociales en el constitucionalismo contemporáneo, 2a. ed., México, El Colegio Nacional-UNAM, Instituto de Investigaciones Jurídicas, 2011.

_-_, "Igualdad, no discriminación (y políticas públicas): A propósito de la constitucionalidad o no del artículo 68 de la Ley General de Población”, en De la Torre Martínez, Carlos (coord.), El derecho a la no discriminación, México, UNAM, Instituto de Investigaciones Jurídicas, 2006.

- - - "Constitución, democracia y derecho: teoría constitucional y valores constitucionales", Revista del Instituto de la Judicatura Federal, núm. 13, 2003.

García BeAudoux, et. al., Comunicación política y campañas electorales. Estrategias en elecciones presidenciales, Barcelona, Gedisa, 2007.

GRIMM, Dieter, “¿Retorno a la comprensión liberal de los derechos fundamentales?", Constitucionalismo y derechos fundamentales, estudio preliminar de Antonio López Pina, Madrid, Trotta, 2006.

Habermas, Jürgen, Historia y crítica de la opinión pública, La transformación estructural de la vida pública. Barcelona, G. Gili, 1981.

Hernández, María del Pilar, "Institucionalidad electoral y derechos políticos de las mujeres", Revista Mexicana de Derecho Electoral, núm. 3, México, UNAM, Instituto de Investigaciones Jurídicas, enero-junio 2013.

- _ - "Los límites al control de constitucionalidad", en AstudiLlo, César y Córdova Vianello, Lorenzo, Reforma y control de la Constitución. Implicaciones y límites, México, UNAM, Instituto de Investigaciones Jurídicas, 2011.

IFE, Administración del tiempo del Estado en radio y televisión para fines electorales, México, IFE, 2008.

JuÁrez GÁmiz, Julio, Brambila, José Antonio, "Contenido y estructura de la publicidad política televisiva en el proceso electoral federal 2012", Revista Mexicana de Derecho Electoral, núm. 3, México, UNAM, Instituto de Investigaciones Jurídicas, enero-junio 2013.

Lazarsfeld, Paul y Katz, Elihu, La influencia personal, Barcelona, Ed. Hispano Europea, 1979.

Madrazo Lajous, Alejandro, "Libertad de expresión y equidad. La reforma electoral de 2007 ante el Tribunal Electoral", Cuadernos de divulgación de la Justicia Electoral, México, TEPJF, núm. 5, 2008. 
Esta revista forma parte del acervo de la Biblioteca Jurídica Virtual del Instituto de Investigaciones Jurídicas de la UNAM

Manheim, Ernst, La opinión pública, Madrid, Ed. Rev. Derecho Privado, 1936.

Mazzoleni, Gianpietro, La comunicación política, trad. de Josefa Linares de la Puerta, Madrid, Editorial Alianza, 2010

Polo SABAU, José Ramón, Libertad de expresión y derecho de acceso a los medios de comunicación, Madrid, Centro de Estudios Políticos y Constitucionales, 2002.

PNUD, La democracia en América Latina. Hacía una democracia de ciudadanos y ciudadanas, Argentina, Aguilar-Altea-Taurus-Alfaguara, 2004.

Rabasa Gamboa, Emilio, Las reformas constitucionales en materia político-electoral, México, PNUD-UNAM, Instituto de Investigaciones Jurídicas, 2012.

Relatoría especial para la libertad de expresión, Marco Jurídico Interamericano sobre el derecho a la libertad de expresión, OEACIDH, 2010.

Rosas Martínez, Alejandro, “¿Derecho de rectificación, derecho de respuesta o derecho de réplica?", Derecho Comparado de la Información, México, núm. 18, julio-diciembre de 2011.

Rospir, Juan Ignacio, "Introducción a la comunicación política”, en Salomé Berrocal, Gonzalo (coord.), Comunicación política en televisión y nuevos medios, Barcelona, Ariel, 2003.

SABA, Roberto, "El derecho de la persona a acceder a la información en poder del gobierno", Derecho Comparado de la Información, núm. 3, enero-junio de 2004.

Sunstein, Cass, República.com: Internet, democracia y libertad, México, Paidós, 2003.

Steinberg, Ch. S., Los medios de comunicación social, México, Editorial Roble, 1969.

Treves, Renato, El juez y la sociedad, Madrid, Cuadernos para el Diálogo, 1974.

Villanueva, Ernesto, "Derecho de Acceso a la Información Pública”, en Latinoamérica: Estudio Introductorio y Compilación, México, UNAM, Instituto de Investigaciones Jurídicas, 2003, p. XVII.

Viola, Francesco, y Zaccaria, Giuseppe, Derecho e interpretación. Elementos de teoría hermenéutica del derecho, Madrid, Instituto de Derechos Humanos Bartolomé de las Casas, Universidad Carlos III, Dykinson, 1999. 
Esta revista forma parte del acervo de la Biblioteca Jurídica Virtual del Instituto de Investigaciones Jurídicas de la UNAM

Woldenberg, José, Comunicación Política, Medios y Elecciones, México, AMEDI, abril 2011.

Wright Mills, Charles, La élite del poder, México, Fondo de Cultura Económica, 1975.

Zagrebelsky, Gustavo, El derecho dúctil. Ley, derechos, justicia, trad. Marina Gascón, 2a. ed., Madrid, Trotta, 1997. 